\title{
SELEÇÃO DE HOSPEDEIROS E DETERMINAÇÃO DA FAIXA DE TEMPERATURA IDEAL PARA A CRIACÃO DO ENDOPARASITO DE PUPAS DE LEPIDÓPTEROS Brachymeria (B.) ovata (SAY, 1824) (HYMENOPTERA, CHALCIDIDAE) EM LABORATÓRIO
}

\author{
ACACIO GERALDO DE CARVALHO \\ Engenheiro Florestal
}

Orientador: Dr. EVONEO BERTI FILHO

Dissertação apresentada à Escola Superior de Agricultura "Luiz de Queiroz", da Universidade de São Paulo, para obtenção do título de Mestre em Engenharia Florestal.

PIRACICABA

Estado de São Paulo - Brasil

Noyembro, 1984 


\author{
A minha esposa Sonia Maria \\ e às minhas filhas Maria Angēlica \\ e Cassiane Alice, \\ DEDICO.
}

\author{
A minha mãe, \\ ao meu pai, \\ a minha cunhada Libia Maria \\ ao meu sobrinho Alexander \\ OFEREÇO.
}


AGRADECIMENTOS

0 Autor expressa seus sinceros agradecimentos a todas as pessoas e instituições que, direta e indiretamente, colaboraram para a realização do curso de Pós-Graduação em Engenharia florestal e na execução deste trabalho, especialmente ãs relacionadas a seguir:

- A Universidade Federal Rural do Rio de Janeiro, principalmen te aos professores: Hugo Barbosa Amorim; José Carlos Franque; Adriano Lücio Peracchi: Hugo Edison Barbosa de Rezende, e Ricardo da Silva Pereira, pela oportunidade e confiança.

- Ao Dr. Evoneo Berti Filho, Professor Adjunto do Departamento de Entomologia da ESALQ/USP, pela orientação e constante incentivo na execução e pela versão do resumo para o inglés.

- Ao Professor Dr. Orlando Shigueo Ohashi, da Faculdade de Ciências Agrárias do Pará, pelas sugestões e estímulos.

- Ao Professor Dr. Paulo Yoshio Kageyama, pela oportunidade e apoio.

- Aos Professores dos Cursos de Pós-Graduação em Engenharia Florestal e Entomologia, pelos valiosos ensinamentos transmi tidos. 
- A Dra. Marinéia de Lara Haddad, da Empresa Brasileira de Pes quisa Agropecuāria, pelas anālises estatisticas.

- A CAPES pela concessão de bolsa de estudo.

- Ao Planalsucar, na pessoa do Engo Agronómo M.S. Pauro Sergio Machado Botelho, pelo fornecimento de material para execução de alguns experimentos.

- Aos alunos dos Cursos de Pós-Graduação em Engenharia Florestal e Entomologia da ESALQ, pela amizade.

- Aos funcionārios dos Departamentos de Silvicultura e Entomologia, da Secretaria de Pós-Graduação e da Biblioteca da ESALQ, pela atenção e serviços prestados. 


\section{$\bar{I} N D$ I C E}

Pāgina

RESUMO.

vii

SUMMARY.

$i x$

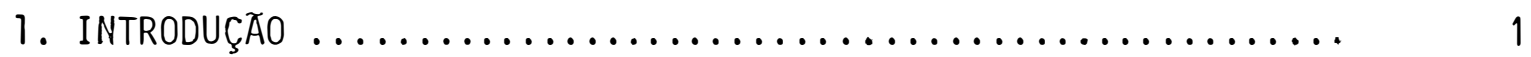

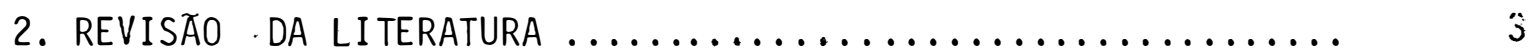

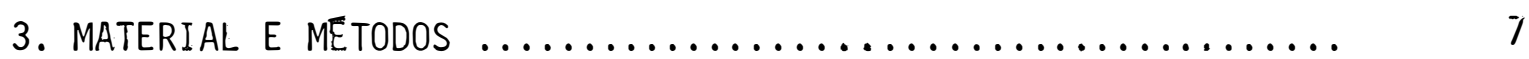

3.1. Parasito $. . . \ldots \ldots \ldots \ldots \ldots \ldots \ldots \ldots \ldots \ldots \ldots \ldots \ldots \ldots, 7$

3.2. Ciclo de B. ovata em temperaturas constantes ......... ic

3.2.1. Ensaios instalados ..................... 10

3.2.2. Seleção das pupas $\ldots \ldots \ldots \ldots \ldots \ldots \ldots \ldots \ldots . . \ldots \ldots$

3.2.3. Oviposição $\ldots \ldots \ldots \ldots \ldots \ldots \ldots \ldots \ldots \ldots \ldots$

3.2.4. Emergência do parasito .................. 14

3.3. Determinação da temperatura base $\left(T_{b}\right)$ e da constante térmica $(K)$ de B. ovata ........................ 14

3.4. Preferência para oviposição $\ldots \ldots \ldots \ldots \ldots \ldots \ldots \ldots . .15$

3.5. Parasitismo em pupas encasuladas .............. 15

3.6. Longevidade em função da alimentação ............... 16

3.7. Anālise estatistica $\ldots \ldots \ldots \ldots \ldots \ldots \ldots \ldots \ldots . \ldots \ldots \ldots$

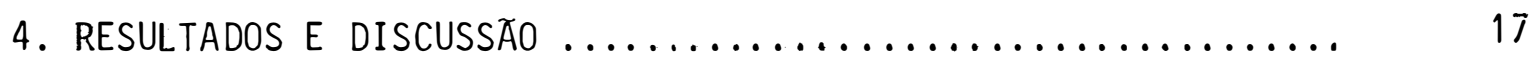

4.1. Ciclo em temperaturas constantes ............... 17

4.1.1. Ensaio I - Galleria mellonella (L., 1750) ..... 17

4.1.2. Ensaio II - Diatraea saccharalis (Fabricius,

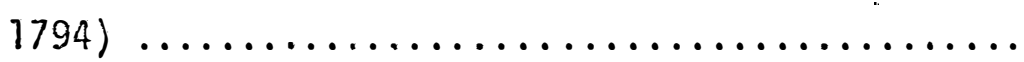

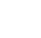

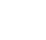

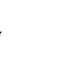

7

4

\section{4} 5. 6 6 7 7 
Pāgina

4.1.3. Ensaio III - Alabama argillacea (Hubner, 1818).. 25

4.1.4. Ensaio IV - Melanolophia sp. ............. 29

4.1.5. Ensaio V - Anagasta kuehniella (Zeller, 1879)... 32

4.1.6. Ensaio VI - Agrotis ipsilon (Hufgnage 1, 1776)... 36

4.2. Comparação dos ciclos e porcentagem de emergência de $B$. ovata nos diferentes hospedeiros $\ldots \ldots \ldots \ldots \ldots \ldots \ldots . \quad 39$

4.2.1. Comparação dos ciclos ................... 39

4.2.2. Comparação de porcentagem de emergência .... 42

4.3. Temperatura base $\left(T_{b}\right)$ e constante térmica $(K)$ de $B$. ovata ................................ 44

4.4. Preferência para oviposição de B. ovata ............ 49

4.5. Parasitismo em pupas encasuladas ............... 51

4.6. Longevidade em função da alimentação ............. 52

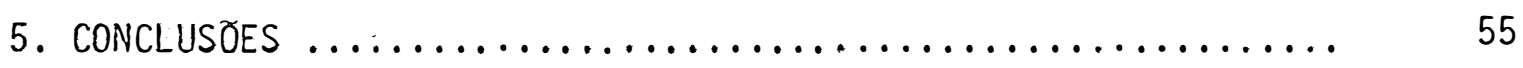

6. LITERATURA CITADA $\ldots \ldots \ldots \ldots \ldots \ldots \ldots \ldots \ldots \ldots \ldots \ldots \ldots \ldots \ldots \ldots \ldots \ldots$

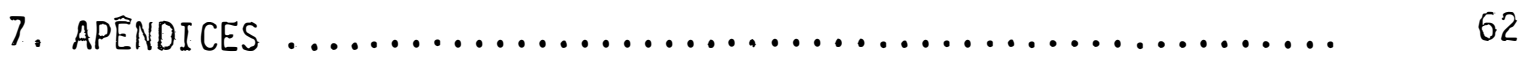


.$v i \mathrm{i}$.

SELEÇ̃̃O DE HOSPEDEIROS E DETERMINACÃO DA FAIXA DE

TEMPERATURA IDEAL PARA A CRIAÇÃO DO ENDOPARASITO

DE PUPAS DE LEPIDÓPTEROS Brachymeria (B.) ovata

(SAY, 1824) (HYMENOPTERA, CHALCIDIDAE) EM LABORATÓRIO

\author{
Autor: ACÁCIO GERALDO DE CARVALHO \\ Orientador: Dr. EVONEO BERTI FILHO
}

\title{
RESUMO
}

Este trabalho trata da seleção de hospedeiros e da determinação da faixa de temperatura ideal para a criação do endoparasito Brachymeria (B.) ovata (Say, 1824) (Hymenoptera, Chalcididae), em laboratōrio. Foram utilizadas câmaras climatí zadas reguladas às temperaturas de $18,20,22,25,30$ e $320 \mathrm{C}$. o experimento foi desenvolvido no Departamento de Entomologia da Escola Superior de Agricultura "Luiz de Queiroz", em Piraci caba, SP. Como hospedeiros foram utilizadas pupas das seguintes espécies da Ordem Lepidoptera: Anagasta kuenniella (Zeller, 1879), Diatraea saccharalis (Fabricius, 1794), Galleria mellonella (Linnaeus, 1750) (Pyralidae), Alabama argillacea (Hübner, 1818), Agrotis ipsilon (Hufnagel, 1776) (Noctuidae) e Melanolophia sp. (Geometridae). Com os dados dos ciclos biológicos nos diferentes hospedeiros determinou-se a temperatura ba- 
se e a constante térmica, pelo método da hipérbole. os resulta dos indicaram que: Galleria mellonella (L.) è o melhor hospedeiro para a multiplicação de B. ovata; a faixa ideal para a multiplicação do parasito é de 25 a $30^{\circ} \mathrm{C}$; a fémea do parasito tem preferēncia para ovipositar em pupas de G. mellonella; as fémeas ovipositam em pupas protegidas por casulo de seda; os adultos do parasito alimentados somente com mel têm maior longevidade. 


\author{
HOST SELECTION AND DETERMINATION OF THE OPTIMAL \\ TEMPERATURE RANGE FOR REARING THE ENDOPARASITE OF \\ LEPIDOPTERAN PUPAE Brachymeria (B., ) ovata \\ ( SAY, 1824) ( HYMENOPTERA, CHALCIDIDAE) IN LABORATORY
}

Author: ACÁCIO GERALDO DE CARVALHO Adviser: Dr. EVONEO BERTI FILHO

\title{
SUMMARY
}

This paper deals with the host selection by the endoparasite Brachymeria (B.) ovata (Say, 1824) (Hymenoptera, Chalcididae), and the optimal temperature range for rearing the parasite in laboratory, by using climatic chambers kept at 18 , $20,22,25,30$, and $32^{\circ} \mathrm{C}$. The experiment was set in the Department of Entomology of the "Escola Superior de Agricultura Luiz de Queiroz", in Piracicaba, State of São Paulo, Brazil. The species of lepidopteran pupae used as hosts were: Anagasta kuenniella (Zeller, 1879), Diatraca saccharalis (Fabricius, 1794), Galleria mellonella (Linnaeus, 1750) (Pyralidae), Alába ma argillacea (Hübner, 1818), Agrotis ipsilon (Hufnagel, 1776) (Noctuidae), and Melanolophia sp. (Geometridae). The temperatu re treshold and the thermal constant were determined with the data of the parasite's life cycles in different hosts, by the 
hyperbole method. The results have indicated that: $G$. mellonella is the best host to rear $B$. ovata; the optimal tem perature range for rearing the parasite is from 25 to $30^{\circ} \mathrm{C}$; B. ovata females prefer to oviposit on $G$. mellonella pupae; B. ovata females do oviposit on pupae protected by cocoons; aduits of the parasite live longer when fed with honey. 


\section{INTRODUCÃO}

As pupas de um grande número de lenidópteros de importāncia agrícola e florestal são parasitadas por Brachymeria ovata (Say, 1824) (DE SANTIS, 1980 e BERTI FILHO, 1981).

No Brasil estudo realizado por OHASHI (1978), mos trou que B. ovata parasitou cerca de $80 \%$ das crisālidas de Eupseudosoma aberrans Schaus, 1905 e E. involuta (Sepp, 1952), em eucaliptais do municipio de Tupaciguara, em Minas Gerais. Neste trabalho observou-se que esse parasitóide ataca outras pragas importantes do eucalipto como Thyrinteina arnobia (Stol1, 1372), Sarsina violacens (Herrich-Schaeffer, 1856), Euselasia euploea eucerus (Hewitson, 1872) e Glena sp. Ainda GALLO et alii (1978) citam B. ovata como eficiente parasito de Euselasia apisaon (Dalman, 1823), outra praga de eucalipto no Brasil Central.

PATANA et alii (1978) e PATANA (1979) estudaram 
a viabilidade de produzir esse parasitóide em laboratório para o controle de Hemileuca oliviae Cockerel no Novo México, nos Estados Unidos da América.

Apesar de ser o controle biológico em fiorestas jā bastante desenvolvido e estudado em vārios paîses, no Brasil hā apenas trabalhos esparsos nesta ārea. Embora sua impor tância há muito tempo seja reconhecida, poucos pesquisadores se dedicam a esse estudo.

o reconhecimento da importāncia do controle biológico segue paralelo ao aumento dos plantios florestais, em grande escala, principalmente de Eucalyptus e Pinus. Sendo culturas homogèneas extensas, podem ser atacadas por diversas pragas que ai encontram habitat adequado ao seu desenvolvimento.

Considerando que, ro controle de pragas florestais, o controle biológico tem se mostrado o mais adequado e eficiente (BERTI FILHO, 1981) e dada a importância de Brachyme ria ovata no controle natural de algumas pragas florestais (OHASHI, 1984), elaborou-se o presente trabalho, que tem como objetivo bāsico a seleção de hospedeiros para criação, em 1 ar ga escala, deste parasitóide, como tambēm obter a faixa ideal de temperatura para multiplicação em laboratório, para uso em programas de controle biológico. Foram determinados também os seguintes parâmetros: preferēncia para oviposição; parasitismo em pupas encasuladas e longevidade em função da alimentação. 


\section{REVISÃO DE LITERATURA}

Segundo DOWDEN (1935) a maioria das espécies do gênero Brachymeria é encontrada nos climas tropicais e subtropicais, entretanto aigumas espécies são comuns na zona temperada. O gēnero Brachymeria Westwood, 1829, era incluído em Chalcis e apresentava mais de 150 espécies.

BURKS (1936) estudou cinco espécies de Brachymeria no Estado de Illinois, nos Estados Unidos, e descreveu alguns caracteres morfológicos de $B$. ovata, inclusive apresentando figuras de cabeça, tórax e edeago.

BURKS (1960) revisou o gênero Brachymeria, estudando 27 espécies da América do Norte. Elaborou uma cha ve para essas espécies, e B. ovata foi descrita baseando-se na fémea. 0 gênero Brachymeria foi subdivido em cinco subgêneros e B. ovata foi classificada no subgēnero Brachymeria. Neste trabalho apresentou-se figuras das faces laterais da cabeça, pronoto e fémur posterior, onde existem ca- 
racteres considerados importantes para diferenciar B. ovata das demais. Observou que B. ovata distribui-se pelas regiós Neärticas e Neotropical como parasito primārio de pupas de mais de 100 espēcies em 18 familitas de Lepidoptera.

No Brasil B. ovata jā foi encontrada nos seguintes hospedeiros pertencentes à ordem Lepidoptera: Spodoptera frugiperda, Plusia nu, Alabama argillacea, Eupseudosoma aberrans, Eupseudosoma involuta, Sarsina violascens, Euselasia api saon, Euselasia sp., Ascia monuste orseis, Papilio thoas thoan tiades, Hedylepta indicata, Thyrinteina arnobia, oxydia sp. e Glena sp. (COSTA LIMA, 1962; SILVA et alii, 1968; De SANTIS, 1969; GALLO et alii, 1978; OHASHI, 1978; BERTI. FILHO, 1981; BORTOLI et alii, 1982 e OHASHI, 1984).

HORN (1974), estudando parasitos primārios e secundārios de pupa de Phyganidia californica (Lepidoptera, Dioplidae), no estado da Califórnia, citou B. ovata como um impor tante parasito primário.

PATANA et alii (1978), estudando o desenvolvimen to de B. ovata em seis hospedeiros, sob cinco temperaturas cons tantes, observaram que: em Pectinophora gossypiella, houve uma variação de $10,4 \pm 0,7$ dias a $57,1 \pm 2,1$ dias, respectivamente, à $350 \mathrm{C}$ e 150C; em Trichoplusia ni e Spodoptera exigua variou de $11,5 \pm 0,6$ dias a $28,9 \pm 1,6$ dias, respectivamente, $\bar{a} 350 \mathrm{C}$ e 200C; em Heliothis virescens, H. Zea e Estigmene acrea, vari ou de $12,2 \pm 0,8$ dias a $34,6 \pm 7,4$ dias, respectivamente à 
$350 \mathrm{C}$ e $200 \mathrm{C}$. Tendo considerado a temperatura de $150 \mathrm{C}$ próxima a temperatura base, porque poucos exemplares desenvolveram-se nessa temperatura, e a faixa de $250 \mathrm{C}$ à $300 \mathrm{C}$ como ótima para o desenvolvimento, embora a de $300 \mathrm{C}$ parecesse ser a melhor para a produção do parasito em laboratōrio.

Estudo realizado por OHASHI (1978) mostrou que B. ovata parasitou cerca de $80 \%$ das pupas de Eupseudosoma aber rans Schaus, 1905 e E. involuta (Sepp, 1852), em eucaliptais do municipio de Tupaciguara em Minas Gerais, sendo o mais eficiente parasitóide. Observou que esse parasitóide ataca outras pragas importantes do eucalipto como: Thyrinteina arnobia (Sto11, 1872); Euselasia euploca eucerus (Hewitson, 1872) e Glena sp.

A fase adulta de B. ovata foi estudada sob quatro temperaturas constantes por PATANA (1979). Os periodos de pré-oviposição, oviposição e longevidade aumentaram quando a temperatura variou de $350 \mathrm{C}$ para $200 \mathrm{C}$. A temperatura mais adequada foi a de $300 \mathrm{C}$, devido a maior progênie por fêmea e também ao nūmero de fêmeas por progênie. Os machos desenvolvidos à $350 \mathrm{C}$ foram geralmente estēreis e as fémeas não copuladas pro duziram apenas machos em todas as temperaturas estudadas.

De SANTIS (1980), ao identificar i6 espécies do gēnero Brachymeria que ocorrem no Brasil, classificou B. ovata se undo a divisão elaborada por Burks, 1960 .

THOMPSON (1981), trabalhando com dietas quimicamente definidas, demonstrou que a larva de $B$. ovata necessita 
de 10 aminoäcidos essenciais: arginina, histidina, isoleucina, leucina, lisina, metionina, fenilamina, treonina, triptofano e valina.

OHASHI (1984) relatou que em diversas coletas de pupas de Eupseudosoma aberrans. Eupseudosoma involuta (Lep., Arctiidae), Oxydia sp., Glena sp.. Thyrinteina arnobia (Lep., Geometridae) e Psorocampa denticulata (Lep. Notodontidae) em eucaliptais de Tupaciguara (MG), Altinōpolis, Mogi-guaçu e It u peva (SP) somente a ūltima espēcie não foi parasitada por $B$. ovata, apesar de ter sido coletado um grande nümero de pupas desse lepidōptero no mesmo plantio em Altinópolis (SP), onde as cinco outras espécies apresentavam-se parasitadas por $B$. ovata. 


\section{MATERIAL E METODOOS}

O trabalho foi desenvolvido nos laboratórios do Departamento de Entomologia da Escola Superior de Agricultura "Luiz de Queiroz", da Universidade de São Paulo, em Piracicaba, no período de 01.12 .83 a 20.08 .84 .

\subsection{Parasito}

A colonia inicial dos parasitos foi obtida de criação de laboratōrio em pupas de spodoptera frugiperda (Smith, 1797 ) (Lep., Noctuidae). Para manutenção da população foram utilizadas, como hospedeiro alternativo, pupas de Galleria mellonella (L., 1750) com um dia de idade e cuja criação foi mantida continuamente em laboratório sobre dieta de acordo com a composição e preparação citadas por GUERRA (1973). 
Os casais foram mantidos em mangas de vidro (com 18 e $10 \mathrm{~cm}$ de altura e 10 e $7 \mathrm{~cm}$ de diâmetro, respectivamente), com tela na parte superior; na parte inferior, uma placa de pe tri de vidro (com $15 \mathrm{~cm}$ de diâmetro or $1,5 \mathrm{~cm}$ de altura), for rada com papel filtro. (Figura 1 ).

Para alimentação, utilizou-se frascos de vidro com 4,5 cm de altura, tampados com esponjas de dupla face conforme idealizado por OHASHI 1978, contendo uma camada de mel puro na face comporos maiores e àgia no frasco. o mel e a água foram trocados a cada quatro dias. (Figura 2).

0 ambiente utilizado para manutenção dos adultos de $B$. ovata constituiu-se de uma sala iluminada artificialmente por quatro conjuntos de duas lâmpadas fluorescentes, tipo 1 uz do dia, de 40 watts cada, a dois metros de altura acima das mesas, onde se colocaram as gaiolas com os parasitos.

0 fotoperiodo foi controlado em 14 horas, a temperatura e umidade relativa foram mantidas em $26 \pm 10 \mathrm{C}$ e 67 $\pm 6 \%$, respectivamente, por um aparelho de ar condicionado tipo "quente-frio" e registrados por um termo-higrógrafo. 


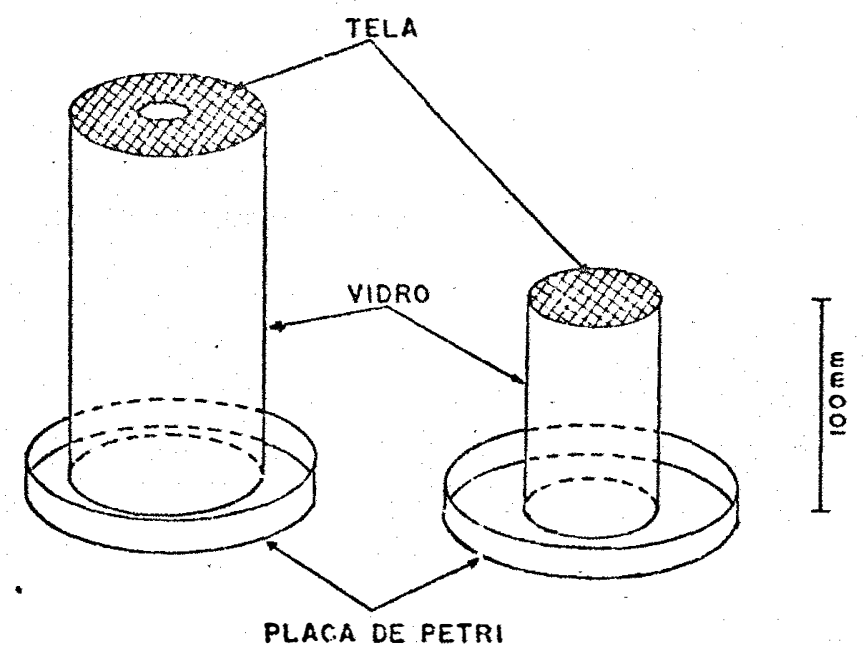

Figura 1 - Gaiolas de vidro com uma das faces telada, apoiada sobre placas de Petri, usadas para emergéncia e criação de B. ovata (OHASHI, 1978).

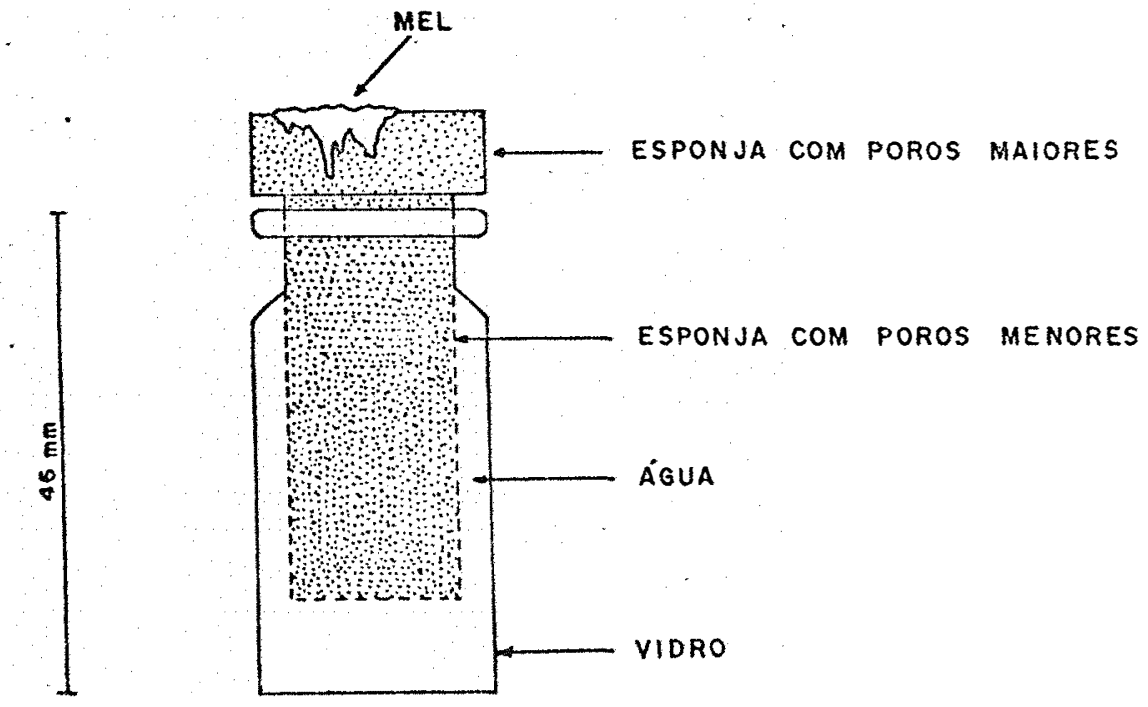

Figura 2 - Frásco de vidro com esponja plästica, utilizado para servir água e mel aos adultośs de B. ovata (OHASHI, 1978). 


\subsection{CICLO DE B. ovata EM TEMPERATURAS CONSTANTES}

\subsubsection{Ensaios instalados}

Foram instalados 6 ensaios (E) em câmaras climatizadas BOD modelo $347 G$ FANEM, reguladas para $14 \mathrm{~h}$ de fotofase, onde se observou o ciclo do parasito (ovo até a emergência do adulto). Cada ensaio constou de uma espécie hospedeira da ordem Lepidoptera em temperaturas constantes, com seis repetições de cinco pupas por hospedeiro, conforme esquema a seguir:

E. I

Galleria mellonella (L., 1750) (Pyralidae) nas temperaturas constantes de: $18,20,22,25,30$ e $320 \mathrm{C}$.

A criação da espécie foi realizada no Laboratório de Controle Biológico da ESALQ, em dieta artificial referi da no item 3.1.

\section{E. II}

Diatraea saccharalis (Fabricius, 1794) (Pyrali -

dae) nas temperaturas referidas no ensaio I.

As pupas desta espécie foram fornecidas pelo Laboratōrio do PLANALSUCAR, Araras - S.P., criadas sobre dieta artificial. 


\section{E. I I}

Alabama argillacea (Hubner, 1818) (Noctuidae) nas temperaturas referidas no ensaio I.

A criação da espécie foi realizada no Laboratório de Controle Biológico da ESALQ, sob dieta natural de folhas de algodão.

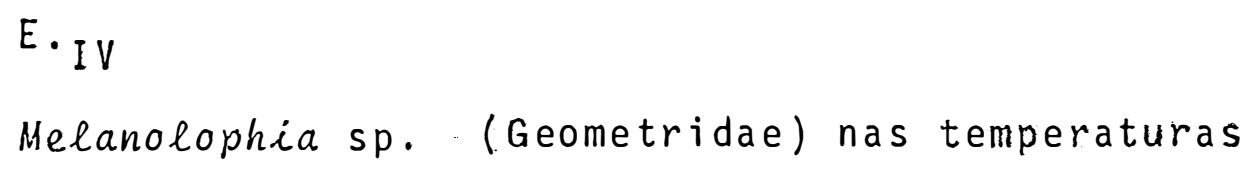

As pupas utilizadas na montagem deste ensaio foram coletadas em plantio de Pinus patula na fazenda Santa Mari na de propriedade da Companhia Melhoramentos de Papel e Celulo. se no Municipio de Bragança Paulista - SP, obtidas de um surto ocorrido no povoamento de Pinus patula em janeiro de 1984.

\section{$E \cdot V$}

Anagasta kuehniella (Zeller, 1879) (Pyralidae) nas temperaturas de: $22,25,30$ e $32^{\circ} \mathrm{C}$.

As pupas desta espécie foram fornecidas pelo Labo ratōrio de Biologia da ESALQ, criadas sobre dieta de farelo de trigo. 


\section{$E \cdot V I$}

Agrotis ipsilon (Hufnagel, 1776) (Noctuidae) nas temperaturas de: 18,20 e $220 \mathrm{C}$.

A criação da espécie foi realizada no Laboratório de Controle Biológico da ESALQ, sob dieta natural de folhas de batata doce.

\subsubsection{SELECÃo DAS PUPAS}

Nesta etapa procurou-se selecionar pupas vivas, com um dia de idade e sadias.

Na criação de G. mellonella e A. kuehniella, por se tratarem de insetos encasulados, a empupação foi observada, diariamente, através de uma abertura formada pelo inseto na ex tremidade dos casulos. As pupas foram, então, retiradas dos ca sulos por cortes com tesoura.

Nos lotes de $D$. saccharalis, selecionou-se em função do tamanho,eliminando-se as menores pupas, pois de acor do com ASKEW (1971) e PATANA et alii (1978), o tamanho do hos pedeiro pode influenciar o tamanho do parasito. Ainda segundo RAJAS-ROUSSE e BENOIT (1977), reduz-se a variação de diferentes medidas do parasito, usando-se hospedeiros da mesma idade, pesos idēnticos e contendo apenas um ovo do parasito.

As pupas de A. argillacea e A. ipsilon foram uti lizadas, diariamente, em função da idade. 
As crisālidas de Melanolophia sp., coletadas no campo foram selecionadas por tamanho.

\subsubsection{OVIPosiç̃̃̃o}

As pupas com um a trēs dias de idade colocadas em placa de petri, com auxîlio de pinças, foram submetidas aos parasitos no horārio de 8 às 17:00 horas em grupos de cinco a sete pupas por gaiola. Observado o início da oviposição, pene tração do ovipositor, foram retiradas das gaiolas para a mesa. Terminada a oviposição, o parasito foi recolocado na gaiola. A medida que as pupas foram parasitadas, uma única vez, eram trans portadas, com pinças de ponta curva, para placa de petri (com $15 \mathrm{~cm}$ de diāmetro e $2 \mathrm{~cm}$ de altura) até que a ūltima pupa do dia fosse parasitada.

A seguir as pupas foram individualizadas em tubos de vidro de fundo chato (com $8 \mathrm{~cm}$ de altura e $2 \mathrm{~cm}$ de diâmetro), tampados com chumaço de algodão, agrupados em grades de arame galvanizado, numerados, identificados e datados com canetas hidrocor. As leituras foram realizadas diariamente pa ra se obter os seguintes parãmetros: duração do ciclo, sexo e percentagem de emergência do parasito. 


\subsubsection{Emergéncia do parasito}

Após a emergência registrou-se a duração do ciclo, sendo os parasitos sexados através de um microscópio este reoscópico wild, procurando-se formar o maior nümero possível de casais, acondicionando-os em gaiolas, para constituir a população de manutenção.

As pupas que näo deram origem a parasitos foram dissecadas apōs dez dias do final da emergēncia, através de e $\underline{s}$ tilete, pinça e sob Microscópio Estereoscópio em aumento de $40 x$, anotando-se a fase de paralisação do desenvolvimento do parasito.

\subsection{Determinacĩo da temperatura base $\left(T_{B}\right)$ e da constante TÉRMICA (K) DE B. ovata}

Com os dados de duràção média do ciclo nas tempe raturas e hospedeiros citados no item 3.2.1., estimou-se a tem peratura base ou limiar de desenvolvimento pelo método da hipérbole de HADDAD e PARRA (1984).

os valores de $T_{b}, K, R^{2}$ e os parāmetros a e $\underline{b}$ da regressão $y=a-b x$, foram calculados pelo computador CP500 do Departamento de Entomologia da ESALQ/USP. A partir dessa equação estimou-se a velocidade e a duração de desenvolvimento nas temperaturas estudadas para cada hospedeiro. 


\subsection{Preferéncia para oviposição}

Neste experimento foram feitas seis repetições de cinco pupas, dos seguintes hospedeiros: $D$. saccharalis, G. me $\underline{\ell}$ lonella e A. argillacea, perfazendo um total de 15 pupas por repetição, que foram oferecidas a 15 fémeas do parasito, em uma gaiola, marcando-se o nümero de oviposição por hospedeiro du-rante trinta minutos, sendo posteriormente separadas, individu almente, em tubos de vidro tampados com chumaço de algodão, identificando-se a repetição e a data de postura e submetendo-as à temperatura de $300 \mathrm{C}$, visando a obtenção da porcentagem de emergéncia do parasito.

\subsection{PARASITISMO EM PUPAS ENCASUladAs}

Neste experimento observou-se o comportamento do parasito para oviposição em 30 pupas encasuladas de G. mellonella.

As pupas foram mantidas nas referidas câmaras cli matizadas à temperatura de $300 \mathrm{C}$, individualizadas em tubos de vidro sendo observada, diäriamente, a emergéncia do parasito, ciclo de vida e sexo. 


\subsection{LongeVidade EM Funçĩ̃o da AlimentacÃo}

Neste experimento submeteram-se 65 adultos do para sito às diferentes condições de alimentação e jejum. Os adultos foram mantidos no mesmo ambiente de criação da colónia e submetidos às mesmas técnicas descritas no item 3.1 .

\subsection{AnĀlise estatística}

0 delineamento experimental utilizado para os pa ràmetros: ciclo de vida, porcentagem de emergência e teste de preferência para oviposição foi inteiramente casualizado.

A comparação de médias de ciclo de vida, porcentagem de emergência e preferéncia para oviposição foi feita pe 10 teste de Tukey ao nivel de 5\% de probabilidade.

Os dados de porcentagem de emergência foram trans formados em arc sen $\sqrt{x / 100}$. 
4. RESULTADOS E DISCUSSÃO

4.1. Ciclo em temperaturas constantes

$$
\text { 4.1.1. ENSAIO I - Galleria mellonella (L, 1750) }
$$

O tempo exigido por B. ovata, em pupas de G. mellonella, desde a oviposição à emergēncia dos adultos, variou de 12,09 dias à $30^{\circ} \mathrm{C}$ a 50,24 dias à $180 \mathrm{C}$ (Tabela 1). A anālise estatística demonstrou, pelo teste $F$ (Tabela 2 ), uma alteração nos ciclos de $B$. ovata em pupas de $G$. mellonella muito significativa para temperatura. 
Tabela 1 - Ciclos observados e estimados, em dias, intervalo de variação, porcentagem de emergência de $B$. ovata desenvolvida em pupas de G. mellonella em 6 temperaturas constantes e $14 \mathrm{~h}$ de fotofase.

\begin{tabular}{lcrrrrr}
\hline $\begin{array}{l}\text { Temperaturas } \\
\text { (oc) }\end{array}$ & 18 & 20 & 22 & 25 & 30 & 32 \\
\hline Ciclo observado & 50,24 & 41,41 & 26,70 & 20,02 & 12,09 & 12,59 \\
Ciclo estimado & 60,90 & 36,94 & 26,51 & 18,62 & 12,45 & 10,99 \\
Interv. variação & $45-60$ & $35-48$ & $24-30$ & $18-24$ & $11-15$ & $11-15$ \\
\% emergência & 76,66 & 70 & 73,33 & 80 & 93,33 & 60 \\
\hline
\end{tabular}

Tabela 2 - Anālise de variāncia do ciclo de $B$. ovata em pupas de G. mellonella em 6 temperaturas constantes.

\begin{tabular}{lrrrrr}
\hline Causas da variação & G.L. & S.Q. & Q.M. & F & Nível \% \\
\hline $\begin{array}{l}\text { Tratamentos } \\
\text { Resíduo }\end{array}$ & 5 & 7358,490 & 1477,700 & $347,40^{\star *}$ & 0,00 \\
\hline Total & 30 & 127,090 & 4,236 & & \\
\hline
\end{tabular}

C.V. $=7,572 \%$

0 teste de Tukey a $5 \%$ de probabilidade, para as médias dos ciclos de B. ovata em pupas de G. mellonella (Tabela 3), evidenciou que houve uma diminuição nos ciclos à medida que a temperatura aumentou, estabilizando à 30 e $320 \mathrm{C}$ nas quais os ciclos não apresentaram diferenças significativas. Os dados, dos ciclos médios sob as temperaturas de 20,25 e 30 oc, 
não concordam com os conseguidos por PATANA et alii (1978) e OHASHI (1984) para outros hospedeiros.

Tabela 3 - Teste de Tukey a $5 \%$ de probabilidade para o ciclo de B. ovata em pupas de $G$. mellonella em 6 temperaturas constantes.

\begin{tabular}{ccc}
\hline Temperatura (OC) & \multicolumn{2}{c}{ Média } \\
\hline 18 & 50,243 & $\mathrm{a}$ \\
20 & 41,416 & $\mathrm{~b}$ \\
22 & 26,708 & $\mathrm{c}$ \\
25 & 20,020 & $\mathrm{~d}$ \\
30 & 12,091 & $\mathrm{e}$ \\
32 & 12,596 & $\mathrm{e}$ \\
\hline
\end{tabular}

Considerando a anālise da porcentagem de emergēn cia de adultos do parasito em pupas de G. mellonella, em função da temperatura, pelo teste $F$ (Tabela 4), não houve diferen ça significativa, embora 0 teste de Tukey a $5 \%$ de probabilidade, aplicado às médias de porcentagem de emergēncia dos adul tos (Tabela 5), tenha mostrado que houve diminuição significativa na emergencia entre 30 e $320 \mathrm{C}$. 
Tabela 4 - Anālise de variāncia da porcentagen de emergëncia de $B$. ovata em pupas de G. mellonella em 6 temperaturas constantes.

\begin{tabular}{lrcccc}
\hline Causas da variação & G.L. & S.Q. & Q.M. & F & Nível \% \\
\hline Tratamentos & 5 & 3081,160 & 616,231 & 2,12 iNS & 8,98 \\
Residuo & 30 & 8702,450 & 290,082 & & \\
\hline Total & 35 & 11783,600 & & & \\
\hline C.V. $=26.205$ & & & & & \\
\hline
\end{tabular}

Tabela 5 - Teste de Tukey a 5\% de probabilidade para porcentagem de emergéncia de $B$. ovata em pupas de $G$. mellonella em 6 temperaturas constantes.

\begin{tabular}{cc}
\hline Temperatura $(O C)$ & Média $(\%)$ \\
\hline 30 & $81,145 \mathrm{a}$ \\
25 & $70,384 \mathrm{ab}$ \\
22 & $64,033 \mathrm{ab}$ \\
18 & $63,640 \mathrm{ab}$ \\
20 & $59,606 \mathrm{ab}$ \\
32 & $51,145 \mathrm{~b}$ \\
\hline
\end{tabular}




\subsubsection{ENSAIO II - Diatraea saccharalis (FABRICIUS, 1794)}

O tempo exigido para o desenvolvimento de $B$. ova ta em pupas de $D$. saccharalis variou de 12,39 dias $\bar{a} 300 \mathrm{C}$ a 52,50 dias à $180 \mathrm{C}$ (Tabela 6). A anālise estatística demonstrou, pelo teste $F$ (Tabela 7 ), uma alteração nos ciclos de $B$. ovata em pupas de $D$. saccharalis muito significativa para temperatura.

Tabela 6 - Ciclos observados e estimados, em dias, intervalo de variação, porcentagem de emergência de $B$. ovata desenvolvida em pupas de $D$. saccharalis em 6 temperaturas constantes e 14 h de foto fase.

\begin{tabular}{lrrrrrrr}
\hline $\begin{array}{l}\text { Temperaturas } \\
(\text { OC })\end{array}$ & 18 & 20 & 22 & 25 & 30 & 32 \\
\hline Ciclo observado & 52,50 & 32,75 & 27,87 & 19,17 & 12,39 & 12,46 \\
Ciclo estimado & 50,67 & 34,58 & 26,24 & 19,27 & 13,36 & 11,90 \\
Interv. variação & $51-60$ & $37-35$ & $26-30$ & $18-21$ & $12-14$ & $12-13$ \\
\% emergência & 23,33 & 50 & 66,66 & 63,33 & 63,33 & 80 \\
\hline
\end{tabular}


Tabela 7 - Anālise de variāncia do ciclo de B. ovata em pupas de 0 . saccharalis em 6 temperaturas constantes.

\begin{tabular}{lrrrrr}
\hline Causas da variação & G.L. & S.Q. & Q.M. & F & Nível \% \\
\hline $\begin{array}{l}\text { Tratamentos } \\
\text { Residuo }\end{array}$ & 5 & 6217,980 & 1242,400 & $1486,95 * *$ & 0,00 \\
& 29 & 24,230 & 0,835 & & \\
\hline Total & 34 & 6236,210 & & \\
\hline
\end{tabular}

C.V. $=3,582 \%$

0 teste de Tukey a $5 \%$ de probabilidade, para as médias dos ciclos de $B$. ovata em pupas de $D$. saccharalis (Tabe la 8), evidenciou que houve uma diminuição nos ciclos à medida que a temperatura aumentou, estabilizando-se à 30 e $320 \mathrm{C}$ nas quais os ciclos não apresentaram diferenças significativas. os dados, dos ciclos mëdios sob as temperaturas de 20,25 e $300 \mathrm{C}$, concordam com os observados por PATANA et alii (1978) para ou tros hospedeiros, concördanco também com os obtidos por OHASH I (1984) em pupas de spodoptera frugiperda (J.F. Smith) nas temperaturas de $18,20,22,25,30$ e $320 \mathrm{C}$. 
Tabela 8 - Teste de Tukey a 5\% de probabilidade para ciclo de B. ovata em em pupas de $D$. saccharalis em 6 temperatutas constantes.

\begin{tabular}{cc}
\hline Temperatura $(O C)$ & \multicolumn{1}{c}{ Média } \\
\hline 18 & $52,500 \mathrm{a}$ \\
20 & $32,750 \mathrm{~b}$ \\
22 & $27,875 \quad \mathrm{c}$ \\
25 & $19,110 \quad \mathrm{~d}$ \\
30 & $12,891 \quad \mathrm{e}$ \\
32 & $12,468 \quad \mathrm{e}$ \\
\hline
\end{tabular}

A anālise estatistica da porcentagem de emergēncia de adultos do parasito, em pupas de $D$. saccharalis, em fun ção da temperatura pelo teste $F$ (Tabela 9) mostrou que houve diferença altamente significativa entre as mēdias de porcentagem de emergência.

Tabela 9 - Anāilise de variāncia da porcentagem de emergéncia de $B$. ovata em pupas de $D$. saccharalis em 6 temperaturas constantes.

\begin{tabular}{lrrrrr}
\hline Causas da variação & G.L. & S.Q. & Q.M. & F. & Nivel \% \\
\hline Tratamentos & 5 & 5420,660 & 1084,130 & $3.93^{* *}$ & 0,73 \\
Resíduo & 30 & 8269,520 & 275,651 & & \\
\hline Total & 35 & 13690,200 & & & \\
\hline
\end{tabular}

C.V. $=33,038 \%$ 
0 teste de Tukey a $5 \%$ de probabilidade aplicado às médias de porcentagem de emergéncia (Tabela 10) mostrou que a porcentagem de emergência à 18 era diferente das obtidas à 30 e $32^{\circ} \mathrm{C}$, que não diferiram entre si. A porcentagem de emer gência aumentou proporcionalmente com a temperatura, sendo que a emergencia mais alta ocorreu à $32^{\circ} \mathrm{C}$, fora da faixa obtida por PATANA et alii (1978) e OHASHI (1984).

Tabela 10 - Teste de Tukey a 5\% de probabilidade para porcentagem de emer gência de $B$. ovata em pupas de $D$. saccharalis em 6 temperaturas constantes.

Temperatura (OC) Média (\%)

\begin{tabular}{cc}
32 & $65,751 \mathrm{a}$ \\
30 & $55,572 \mathrm{a}$ \\
22 & $55,367 \mathrm{ab}$ \\
25 & $53,461 \mathrm{ab}$ \\
20 & $45,000 \mathrm{ab}$ \\
18 & $26,359 \mathrm{~b}$ \\
\hline DMS $=29,145$ &
\end{tabular}




\subsubsection{ENSAIO III - Alabama argillacea (HÜBNER, 1818)}

o desenvolvimento de ovo à emergēncia dos adur tos de B. ovata em pupas de A. argillacea variou de 11,62 dias à $320 \mathrm{C}$ a 41,66 dias à $200 \mathrm{C}$ (Tabela 11). A anālise estatística mostrou, pelo teste $F$ (Tabela 12), uma alteração nos ciclos com alta significancia em função da temperatura. Os dados dos ciclos às temperaturas de 20,25 e $300 \mathrm{C}$, não concordam com aqueles conseguidos por PATANA et alie (1978) para outros hospe deiros. Também não concordam com os obtidos por OHASHI (1984) que trabalhou às temperaturas de $18,20,22,25,30$ e $32^{\circ} \mathrm{C}$ com pupas de spodoptera frugiperda.

Tabela 11 - Ciclos observados e estimados, em dias, intervalo de variação, porcentagem de emergência de $B$. ovata desenvolvida em pupas de A. argillacea em 6 temperaturas constantes e $14 \mathrm{~h}$ de fotofase.

\begin{tabular}{lcccccc}
\hline $\begin{array}{c}\text { Temperaturas } \\
(\text { OC) }\end{array}$ & 18 & 20 & 22 & 25 & 30 & 32 \\
\hline Ciclo observado & - & 41,66 & 34,66 & 20,40 & 13,33 & 11,62 \\
Ciclo estimado & - & 46,74 & 31,15 & 20,76 & 13,34 & 11,64 \\
Interv. variação & - & $39-43$ & $31-34$ & $20-23$ & $12-16$ & $11-13$ \\
\% emergēncia & 0 & 16,66 & 13,33 & 26,66 & 43,33 & 20 \\
\hline
\end{tabular}


Tabela 12 - Anālise de varianncia do ciclo de B. ovata em pupas de A. argil lacea em 6 temperaturas constantes.

\begin{tabular}{|c|c|c|c|c|c|}
\hline Causas da variação & G.L. & S.Q. & Q.M. & $F$ & Nivel $\%$ \\
\hline Tratamentos & 4 & 2534,730 & $633^{\prime}, 683$ & $204 ; 62^{\star \star}$ & 0,00 \\
\hline Resíduo & 16 & 49,550 & 3,096 & & \\
\hline Total & 20 & 2584,280 & & & \\
\hline
\end{tabular}

C.V. $=8,077 \%$

Não foi possivel determinar o ciclo de $B$. evata em pupas de A. argillacéa, à temperatura de $180 \mathrm{C}$, pela ausência de emergéncia do parasito 75 dias após a oviposição. Findo este periodo efetuou-se a dissecação das pupas de A. argillacea, não sendo detectada a presença do parasito.

0 teste de Tukey a $5 \%$ de probabilidade, para as médias dos ciclos de B. ovata em pupas de A. argillacea (Tabela 13), demonstrou que houve uma diminuição do ciclo à medida que a temperatura aumentou, estabilizando-se à 30 e $320 \mathrm{C}$ cujos ciclos não apresentaram diferenças significativas. 
Tabela 13 - Teste de Tukey a 5\% de probabilidade para ciclo de B. ovata em pupas de A. argillacea em 6 temperaturas constantes.

\begin{tabular}{cc}
\hline Temperatura (OC) & Média \\
\hline 20 & 41,666 a \\
22 & $34,666 \mathrm{~b}$ \\
25 & $20,400 \mathrm{c}$ \\
30 & $13,333 \mathrm{~d}$ \\
32 & $11,625 \mathrm{~d}$ \\
\hline
\end{tabular}

A anālise estatística da porcentagem de emergēncia de adultos do parasito, em pupas de A. argillacea, em. função da temperatura pelo teste $F$ (Tabela 14), mostrou que houve diferença altamente significativa na porcentagem de emergência. 0 teste de Tukey a $5 \%$ de probabilidade aplicado às médias de porcentagem de emergéncia (Tabela 15) indicou que a porcentagem de emergência a $180 \mathrm{C} \bar{e}$ diferente das que ocorreram à 25 e 300 C. 
Tabela 14 - Anālise de variância da porcentagem de emergência de $B$. ovata em pupas de $A$. argillacea em 6 temperaturas constantes.

\begin{tabular}{lrrrrr}
\hline Causas da variação & G.L. & S.Q. & Q.M. & F & Nível \% \\
\hline Tratamentos & 5 & 5598,270 & 1139,650 & $4,41^{* *}$ & 0,40 \\
Residuo & 30 & 7759,960 & 258,665 & & \\
\hline Total & 35 & 13458,200 & & & \\
\hline C.V. $=76,470 \%$ & & & & & \\
\hline
\end{tabular}

Tabela 15 - Teste de Tukey a $5 \%$ de probabilidade para porcentagem de emergência de B. ovata em pupas de A. argillacea em 6 temperaturas constantes.

\begin{tabular}{cc}
\hline Temperatura $(O C)$ & Média (\%) \\
\hline 30 & $40,966 \mathrm{a}$ \\
25 & $28,470 \mathrm{a}$ \\
32 & $24,043 \mathrm{ab}$ \\
20 & $17,316 \mathrm{ab}$ \\
22 & $15,393 \mathrm{ab}$ \\
18 & $0,000 \mathrm{~b}$ \\
\hline
\end{tabular}




\subsubsection{Ensaio IV - Melanolophia sp.}

- ciclo de B. ovata em pupas de Melanolophia sp. variou de 11 dias à $320 \mathrm{C}$ a 49,5 dias à $180 \mathrm{C}$ (Tabela 16). A aná lise estatistica desses dados mostrou, pelo teste F (Tabela 17), uma alteração nos ciclos de $B$. ovata em pupas de Melanolophia sp., com grande significância em função da temperatura.

Tabela 16 - Ciclos observados e estimados, em dias, intervalo de variação, porcentagem de emergência de $B$. ovata desenvolvida em pupas de Melanolophia sp. em 6 temperaturas constantes de $14 \mathrm{~h}$ de fotofase.

\begin{tabular}{lllllll}
\hline $\begin{array}{l}\text { Temperaturas } \\
(0 \mathrm{C})\end{array}$ & 18 & 20 & 22 & 25 & 30 & 32 \\
\hline Ciclo observado & 49,50 & 53,5 & 26,91 & 19,13 & 12,49 & 11,00 \\
Ciclo estimado & 67,93 & 39,08 & 27,43 & 18,96 & 12,51 & 11,01 \\
Interv. variação & $48-54$ & $50-59$ & $25-29$ & $18-22$ & $11-13$ & 11,00 \\
$\%$ emergência & 13,33 & 16,66 & 36,66 & 40,00 & 50,00 & 10,00 \\
\hline
\end{tabular}


Tabela 17 - Anāilise de variāncia do ciclo B. ovata em pupas de Melanolophia $\mathrm{sp}$. em 6 temperatutas constantes.

\begin{tabular}{lrrrrr}
\hline Causas da variação & G.L. & S.Q. & Q.M. & F & Nivel \% \\
\hline Tratamentos & 5 & 6184,990 & 1237,000 & $757,80 \star \star$ & 0,00 \\
Residuo & 21 & 34,279 & 1,632 & & \\
\hline Total & 26 & 6219,270 & & & \\
\hline C.V. $=4,946$ & $\%$ & & & &
\end{tabular}

0 teste de Tukey a $5 \%$ de probabilidade, para as médias dos ciclos de B. ovata em pupas de Melanolophia sp. (Tabela 18), indicou que os ciclos nas temperaturas de 18, 20, 22 e $250 \mathrm{C}$ foram significativamente diferentes, porém $\bar{a} .30$ e $320 \mathrm{C}$ não houve diferença. Pode-se notar uma diminuição no ciclo com o aumento da temperatura a partir de $200 \mathrm{C}$. 0 ciclo do parasito à $200 \mathrm{C}$ foi maior que à $180 \mathrm{C}$ provavelmente devido a emergência de quatro machos com um ciclo médio de 52,5 dias e uma fêmea com ciclo de 59 dias. Os dados dos ciclos médios sob as temperaturas de 20,25 e $300 \mathrm{C}$, não concordam com os conseguidos por PATANA et alii (1978) e OHASHI (1984) para outros hospedeiros.

A anāilise estatistica da porcentagem de emergência de adultos do parasito em pupas de Melanolophia sp., em função da temperatura pelo teste $F$ (Tabela 19), mostrou que hou ve diferença altamente significativa. O teste de Tukey a $5 \%$ de probabilidade aplicado às médias de porcentagem de emergência 
(Tabela 20) mostrou que a porcentagem de emergéncia a $300 \mathrm{C}$ e diferente daquelas que ocorrem à 18 e $320 \mathrm{C}$, que não diferem en tre si, sendo que ocorreu um aumento em função de maiores temperaturas.

Tabela 18 - Teste de Tukey a 5\% de probabilidade para ciclo de B. ovata em pupas de Melanolophia sp. em 6 temperaturas constantes.

\begin{tabular}{|c|c|c|}
\hline Temperatura $(O C)$ & Mēd & \\
\hline 20 & 53,5 & $a$ \\
\hline 18 & 49,5 & $b$ \\
\hline 22 & 26,916 & c \\
\hline 25 & 19,138 & $d$ \\
\hline 30 & 12,498 & $\mathrm{e}$ \\
\hline 32 & 11 & e \\
\hline
\end{tabular}

Tabela 19 - Anālise de variāncia da porcentagem de emergência de $B$. ovata em pupas de Melanolophia sp. em 6 temperatutas constantes.

\begin{tabular}{lrrrrr}
\hline Causas da variação & G.L. & S.Q. & Q.M. & F & Nivel $\%$ \\
\hline Tratamentos & 5 & 5976,500 & 1195,300 & $6.03^{* *}$ & 0,06 \\
Resíduo & 30 & 5942,390 & 198,080 & \\
\hline Total & 35 & 11918,900 & & \\
C.V. $=50,518 \%$ & & & & & \\
\end{tabular}


Tabela 20 - Teste de Tukey a $5 \%$ de probabilidade para porcentagem de emergência de $B$. ovata em pupas de Melanolophia sp. em 6 temperatu ras constantes.

\begin{tabular}{cc}
\hline Temperatura $(O \mathrm{OC})$ & Mēdia $(\%)$ \\
\hline 30 & $45,000 \mathrm{a}$ \\
25 & $38,855 \mathrm{ab}$ \\
22 & $37,120 \mathrm{abc}$ \\
20 & $19,821 \mathrm{bc}$ \\
32 & $13,282 \mathrm{c}$ \\
18 & $13,077 \quad \mathrm{c}$ \\
\hline
\end{tabular}

DMS $=24,706$

\subsubsection{ENSAIO V - Anagasta kuehniella (ZELLER, 1879)}

0 desenvolvimento de $B$. ovata de ovo à emergéncia dos adultos, em pupas de A. kuehniella, variou de 10,77 dias à $320 \mathrm{C}$ a 27 dias à $220 \mathrm{C}$ (Tabela 21 ). A anālise estatística demonstrou, pelo teste $F$ ( Tabela 22 ), uma alteração nos ciclos de B. ovata em pupas de A. kuehniella, com grande significância em função da temperatura. 
Tabe $7 a 21$ - Ciclos observados e estimados, em dias, intervalo de variação, porcentagem de emergência de $B$. ovata desenvolvida em pupas de A. kuehniella em 4 temperaturas constantes e $14 \mathrm{~h}$ de foto fase.

\begin{tabular}{lcccccc}
\hline $\begin{array}{l}\text { Temperaturas } \\
(\text { oc })\end{array}$ & 18 & 20 & 22 & 25 & 30 & 32 \\
\hline Ciclo observado & - & - & 27,00 & 19,10 & 12,31 & 10,77 \\
Ciclo estimado & - & - & 27,47 & 18,78 & 12,29 & 10,80 \\
Interv. variação & - & - & $26-28$ & $18-20$ & $13-14$ & $10-12$ \\
\% emergência & - & - & 23,33 & 33,33 & 63,33 & 43,33 \\
\hline
\end{tabular}

Tabela 22 - Anālise de variāncia do ciclo de B. ovata em pupas de A. kuehniella em 4 temperaturas constantes.

\begin{tabular}{lrrrrr}
\hline Causas da variação & G.L. & S.Q. & Q.M. & \multicolumn{1}{c}{ F } & Nivel \% \\
\hline Tratamentos & 3 & 758,873 & 252,958 & $923,76^{* *}$ & 0,00 \\
Residuo & 16 & 4,381 & 0,273 & & \\
\hline
\end{tabular}

C.V. $=3,173 \%$ 
0 teste de Tukey a $5 \%$ de probabilidade, para as médias dos ciclos de B. ovata em pupas de A. kuehniella (Tabe1a 23), mostrou que os ciclos diminuem em função do aumento da temperatura, sendo significativamente diferentes.

Tabela 23 - Teste de Tukey a 5\% de probabilidade para o ciclo de B. ovata em pupas de A. kuehniella em 4 temperaturas constantes.

\begin{tabular}{cccc}
\hline Temperatura $(O C)$ & \multicolumn{3}{c}{ Média } \\
\hline 22 & 27 & $\mathrm{a}$ & \\
25 & 19,1 & $\mathrm{~b}$ \\
30 & 12,316 & $\mathrm{c}$ \\
32 & 10,776 & $\mathrm{~d}$ \\
\hline
\end{tabular}

A anālise estatistica da porcentagem de emergēncia de adultos do parasito em pupas de A. kuehniella, em função da temperatura pelo teste $F$ (Tabela 24 ), indicou que não houve diferença significativa ao nivel de $5 \%$ de probabilidade. 0 teste de Tukey a $5 \%$ de probabilidade aplicado às médias de porcentagem de emergência (Tabela 25) demonstrou que as por centagens de emergēncia do parasito em pupas de A. kuehniella não são diferentes nas temperaturas estudadas. 
Tabela 24 - Anālise de variância da porcentagem de emergência de $B$. ovata em pupas de A. kuehniella em 4 temperaturas constantes.

\begin{tabular}{lrrrrr}
\hline Causas da variação & G.L. & S.Q. & Q.M. & F & Nivel \% \\
\hline Tratamentos & 3 & 2347,210 & 782,404 & 2,3 INS & 10,69 \\
Resíduo & 20 & 6764,970 & 338,249 & & \\
\hline Total & 23 & 9172,180 & & & \\
\hline
\end{tabular}

C.V. $=49,555 \%$

Tabela 25 - Teste de Tukey a 5\% de probabilidade para porcentagem de emergência de $B$. ovata em pupas de A. kuchniella em 4 temperaturas constantes.

\begin{tabular}{cc}
\hline Temperatura (OC) & Média (\%) \\
\hline 30 & $50,75140 \mathrm{a}$ \\
32 & $40,96610 \mathrm{a}$ \\
25 & $32,69290 \mathrm{a}$ \\
22 & $24,04330 \mathrm{a}$ \\
\hline DMS $=26,879$ &
\end{tabular}

Em todas as temperaturas notou-se que houve somen te emergencia de machos, isto pode ter ocorrido porque o macho de $B$. ovata atinge a forma adulta com menor quantidade de alimento que as fêmeas e,em muitas espécies, a proporção de sexo é 
bastante influenciada pelo tamanho do hospedeiro, pois hä especies que depositam ovos não fertilizados, que dão origem a machos, sobre hospedeiros de tamanho pequeno (FINNEY e FISHER, 1968).

\subsubsection{ENSAIO VI - Agrotis ipsilon (HUFNAgEL, 1776)}

o indice médio de desenvolvimento de B. ovata em pupas de A. ipsilon variou de 30,95 dias à $220 \mathrm{C}$ a 53,33 dias a $180 \mathrm{C}$ (Tabela 26), sendo estes valores superiores aos encontrados para a maioria dos hospedeiros testados. O ciclo mais longo do parasito neste hospedeiro talvez esteja relacionado com o seu tamanho, pois era o maior entre as espécies testadas e quando se dissecou as pupas havia maior quantidade de mater al não usado pelo parasito, que nos outros hospedeiros.

Tabela 26 - Ciclos observados e estimados, em dias, intervalo de variação, porcentagem de emergência de $B$. ovata desenvolvida em pupas de A. ipsilon em 3 temperaturas constantes e $14 \mathrm{~h}$ de fotofase.

\begin{tabular}{lrrrrrr}
\hline $\begin{array}{l}\text { Temperaturas } \\
\text { (OC) }\end{array}$ & 18 & 20 & 22 & 25 & 30 & 32 \\
\hline Ciclo observado & 53,33 & 49,10 & 30,95 & - & - & - \\
Ciclo estimado & 58,44 & 41,83 & 32,57 & - & - & - \\
Interv. variação & $50-59$ & $47-54$ & $27-37$ & - & - & - \\
\% emergência & 13,33 & 26,66 & 43,33 & - & - & - \\
\hline
\end{tabular}


A anālise estatística dos ciclos de B. ovata em pupas de A. ipsilon demonstrou, pelo teste $F$ (Tabela 27), uma alteração com grande significância em função da temperatura.

Tabela 27 - Anālise de variância do ciclo de B. ovata em pupas de A. ipsilon em 3 temperaturas constantes.

\begin{tabular}{lrrrrr}
\hline Causas da variação & G.L. & \multicolumn{1}{c}{ S.Q. } & Q.M. & F & Níve $\%$ \\
\hline Tratamentos & 2 & 1361,3300 & 680,6630 & $103,68 * *$ & 0,00 \\
Resíduo & 11 & 72,2129 & 6,5648 & & \\
\hline Total & 13 & 1433,5400 & & \\
\hline C.V. $=6,072 \%$ & & & & & \\
\hline
\end{tabular}

0 teste de Tukey a $5 \%$ de probabilidade para as mëdias dos ciclos de B. ovata em pupas de A. ipsilon (Tabela 28) mostrou que os ciclos diminuiram em função do aumento da temperatura, sendo significativamente diferentes. 
Tabela 28 - Teste de Tukey a $5 \%$ de probabilidade para o ciclo de B. ovata em pupas de A. ipsilon em 3 temperaturas constantes.

\begin{tabular}{ccc}
\hline Temperatura $(O C)$ & \multicolumn{1}{c}{ Média } \\
\hline 18 & 53,333 & a \\
20 & 49,100 & b \\
22 & 30,958 & c \\
\hline
\end{tabular}

A anālise estatistica da porcentagem de emergência de adultos do parasito, em pupas de A. ipsilon, em função da temperatura indicou pelo teste $F$ (Tabela 29) que não houve diferença significativa ao nỉvel de $5 \%$ de probabilidade. 0 teste de Tukey a 5\% de probabilidade aplicado às médias de por - centagem de emergência (Tabela 30) demonstrou que as porcentagens de emergência do parasito em pupas de $A$. ipsilon não são diferentes nas temperaturas estudadas.

Tabela 29 - Análise de varianncia da porcentagem de emergência de $B$. ovata em pupas de A. ipsilon em 3 temperaturas constantes.

\begin{tabular}{lrrrrrr}
\hline Causas da variação & G.L. & S.Q. & Q.M. & F & Nível \% \\
\hline Tratamentos & 2 & 1658,540 & 829,271 & $3.19 N S$ & 6,98 \\
Residuo & 15 & 3893,350 & 259,557 & & \\
\hline Total & 17 & 5551,890 & & & \\
\hline C.V. $=58,429 \%$ & & & & &
\end{tabular}


Tabela 30 - Teste de Tukey a $5 \%$ de probabilidade para porcentagem de emergência de $B$. ovata em pupas de $A$. ipsilon em 3 temperaturas constantes.

\begin{tabular}{cc}
\hline Temperatura (OC) & Média (\%) \\
\hline 22 & $38,855 \mathrm{a}$ \\
20 & $28,470 \mathrm{a}$ \\
18 & $15,393 \mathrm{a}$ \\
\hline DMS $=24,138$ &
\end{tabular}

4.2. Comparação dos ciclos e porcentagem de emergência de B. ovata NOS DIFERENTES HOSPEDEIROS

\subsubsection{Comparaç̃̃o dos Ciclos}

Os dados dos ciclos de B. ovata em pupas de $G$. mellonella, D. saccharalis, A. argillacea, Melanolophiasp., A. kuehniella e A. ipsilon (Apêndices 1 a 6) foram compara dos entre os quatro primeiros hospedeiros, por terem sido estudados em todas as temperaturas, através dos teste $F$ e Tukey (Tabelas 31 e 32 ), tendo demonstrado que nas tempera turas de $20,22,25,30$ e $32{ }^{\circ} \mathrm{C}$ o hospedeiro influiu no $\mathrm{c}$ clo de B. ovata. 0 ciclo à $18{ }^{\circ} \mathrm{C}$ para A. argilacea não foi calculado por não haver emergência de adulto do parasito. $\mathrm{Na}$ temperatura de $20^{\circ} \mathrm{C}$ o menor ciclo foi obtido quando cria do em $D$. saccharalis. Na temperatura de $220 \mathrm{C}$ não houve in 
fluência no ciclo de $B$. ovata desenvolvida em pupas de G. mellonella, D. saccharalis e Melanolophia sp.

Nas temperaturas de 25,30 e $32^{\circ} \mathrm{C}$ embora houvesse diferenças significativas no ciclo, para alguns hospedeiros, nada a)teraria a criação do parasito, em algum daqueles hospedeiros, de vido a diferença no ciclo ser em torno de um dia, não levando em consideração o parâmetro porcentagem de emergência.

Portanto, percebe-se que houve uma interação de hospedeiros versos temperaturas, mostrando um comportamento diferencial dos hospedeiros frente às temperaturas ensaiadas.

Tabela 37 - Significância do teste $F$ e coeficiente de variação do ciclo de B. ovata desenvolvida em pupas de G. mellonella, D. saccharalis, A. argillacea e Melanolophia sp. em seis temperaturas constan tes.

\begin{tabular}{ccc}
\hline $\begin{array}{c}\text { Temperatura } \\
\left({ }^{\circ} \mathrm{C}\right)\end{array}$ & Teste $\mathrm{F}$ & $\begin{array}{c}\text { Coeficiente de } \\
\text { variação }(\%)\end{array}$ \\
\hline 18 & $1,46 \mathrm{NS}$ & 5,031 \\
20 & $53,85 * *$ & 6,139 \\
22 & $10,95 * *$ & 6,609 \\
25 & $4,31 *$ & 3,738 \\
30 & $6,28 *$ & 4,092 \\
32 & $12,67 * *$ & 3,501 \\
\hline$* \quad-5 \%$ de probabilidade & & \\
$* *-1 \%$ de probabilidade & & \\
NS - não significativo & &
\end{tabular}


.41.

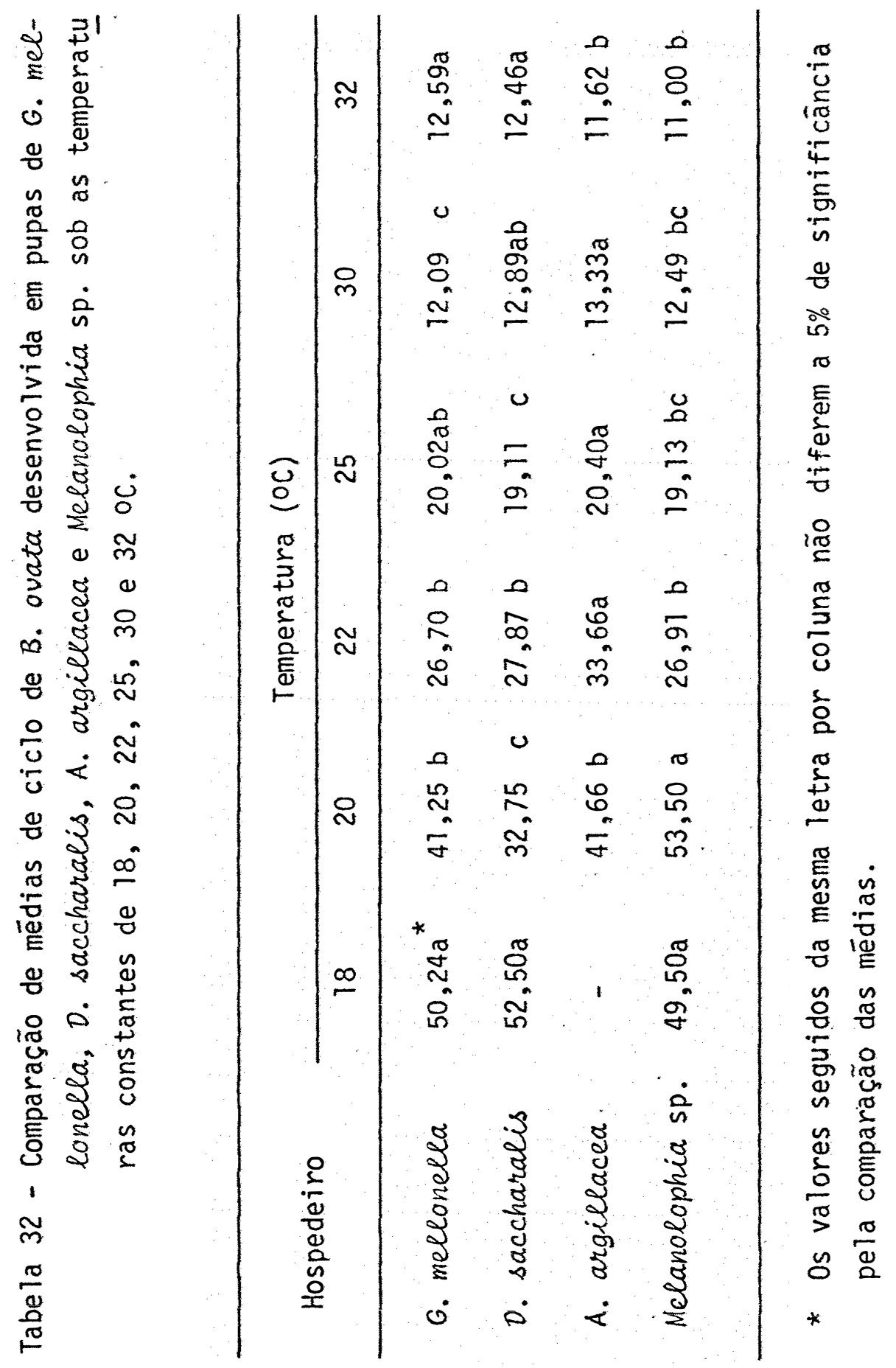




\subsubsection{Comparação de porcentagem de emergência}

As porcentagens de emergência (Apêndice 7) foram comparadas estatisticamente por temperatura e hospedeiro ( $f$ igura 3 ), demonstrando que a maior porcentagem de emergēncia pa ra a maioria dos hospedeiros ocorreu à 25 e $300 \mathrm{C}$, exceto para D. saccharalis que foi $\bar{a} 320 \mathrm{C}$. A maior porcentagem de emergência de B. ovata foi em pupas de G. mellonella à 25 e $300 \mathrm{C}$, tendo apresentado tambēm uma porcentagem maior que nos demais hospedeiros nas temperaturas mais baixas.

Dos dois parámetros analisados, ciclo e porcenta gem de emergencia, para todos os hospedeiros o coeficiente de variação experimental, para ciclo, foi relativamente baixo, mos trando uma boa eficiência para as anālises de variações efetua das. Os resultados obtidos mostram boa precisão.

Por outro lado, para emergência, os coeficientes de variação foram no geral muito altos, não permitindo a detec ção de diferenças entre temperaturas. Dessa forma, diferenças às vezes flagrantes entre tratamentos não se mostraram significativas.

Portanto, jā que a emergência é um parâmetro importante no ciclo, em trabalhos semelhantes deveria ser melhorada a amostragem para os ensaios onde a emergência fosse ava liada. 


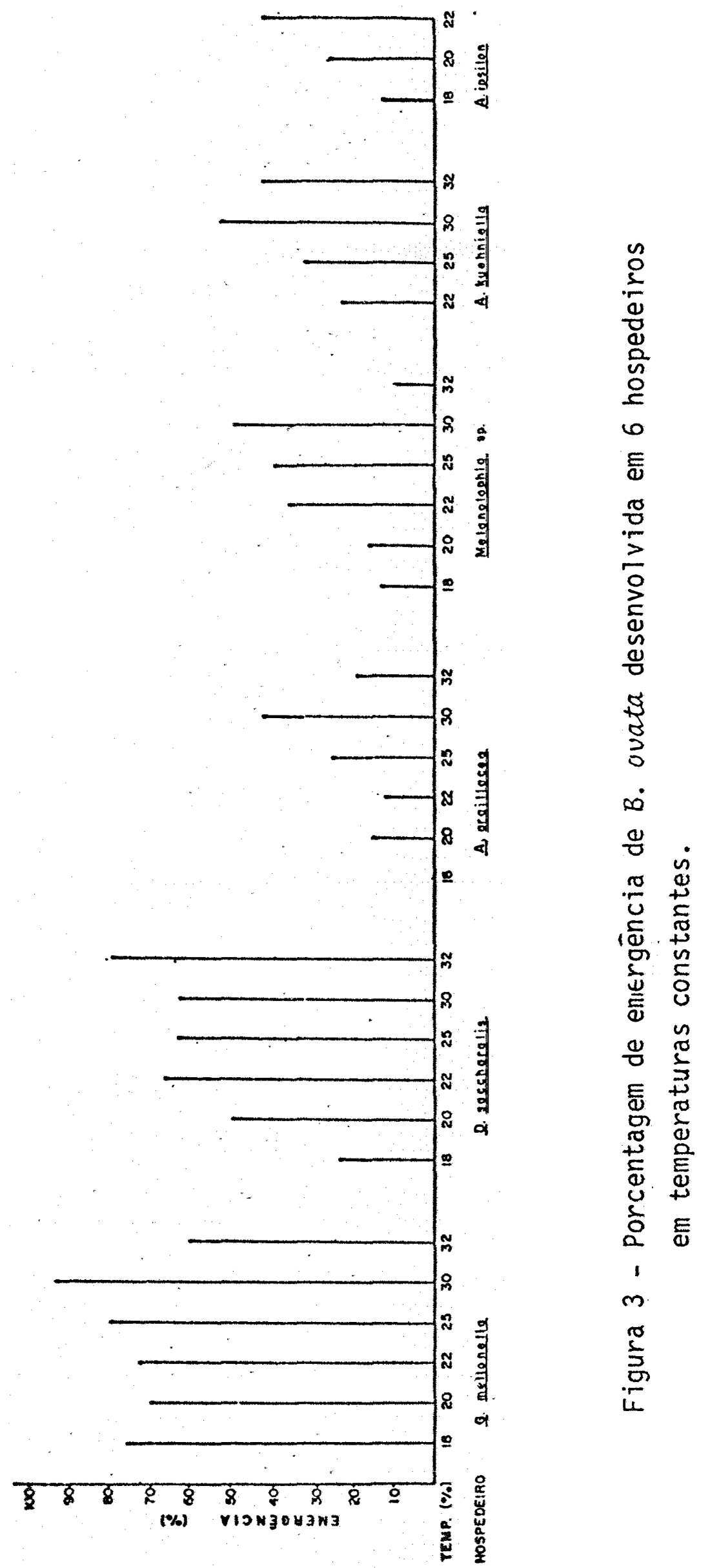




\subsection{Temperatura base $\left(T_{B}\right)$ e constante térmica $(K)$ DE $B$. ovata}

A temperatura base e a constante tērmica para $B$. ovata, determinadas pelo método da hipérbole (Figuras 4 a 9 e Tabela 33), variaram respectivamente de 12,96 a $160 \mathrm{C}$ e 177,9 GD a 294,3 GD. Os resultados de temperatura base se aproximaram muj to da observação de PATANA et alii (1978) os quàis relataram que a temperatura de $150 \mathrm{C}$ está prōxima do limite inferior de desenvolvimento, porque emergiram poucos adultos nesta temperatura. Esses dacios tambēm foram pröximos aos nbtidos por OHASHI (1984).

As estimativas desses parāmetros para B. ovata desenvolvida em pupas de A. ipsilon foram inferiores às determinadas para os demais hospedeiros, provavelmente porque foram estimados com dados de ciclo em trés temperaturas e o minimo exigido pelo método da hipérbole, de acordo com HADDAD e PARRA (1984), são quatro temperaturas. Os valores de $R^{2}$ (Tabela 34) foram inferiores a $90 \%$ somente para a equação de velocidade de desenvolvimento em A. ipsilon; para os demais foram próximos a $100 \%$, o que demonstra uma boa eficiência do método no cálculo de $T_{b}$ e K para B. ovata desenvolvida nos hospedeiros estudados.

Verificou-se que a temperatura afetou intensamen te o desenvolvimento desse parasitóide (Figuras 4 a 9 ).

As estimativas da faixa ótima de desenvolvimento e do limite superior de desenvolvimento pelo método de SAVESCU 
(1965) não foram aceitas para essa espēcie, por terem sido mui to discrepantes aos observados experimentalmente.

Tabela 33 - Temperatura base $\left(T_{b}\right)$ e constante térmica $(k)$ estimadas pelo método da hipērbole para B. ovata desenvolvida em 6 hospedeiros.

Hospedeiro

G. mellonella

D. saccharalis

A. argillacea

Melanolophia sp.

A. kuehniella

A. ipsilon
$T_{b}(O C)$

14,91

13,70

16,00

15,29

15,52

12,96
$K(G D)$

187,8

217,7

184,7

184,1

177,9

294,3

Tabela 34 - Coeficiente de correlação $\left(R^{2}\right)$ e equações da velocidade de de senvolvimento do parasito $B$. ovata em seis hospedeiros, obtidos pelo método da hipérbole.

\begin{tabular}{lll}
\hline \multicolumn{1}{c}{ Hospedeiro } & Eq. ve1. des. $y=a+b x$ & $R^{2}(\%)$ \\
\hline G. mellonella & $y=-0,079405+5,32351 * 10^{-3} x$ & 98,3866 \\
D. saccharalis & $y=-0,062919+4,59177 * 10^{-3} x$ & 98,6893 \\
A. argillacea & $y=-0,085688+5,35415 * 10^{-3} x$ & 99,4112 \\
Melanolophia sp. & $y=-0,083048+5,43152 * 10^{-3} x$ & 98,2981 \\
A. kuehniella & $y=-0,087230+5,61914 * 10^{-3} x$ & 99,9324 \\
A. ipsilon & $y=-0,044046+3,39750 * 10^{-3} x$ & 85,0800 \\
\end{tabular}




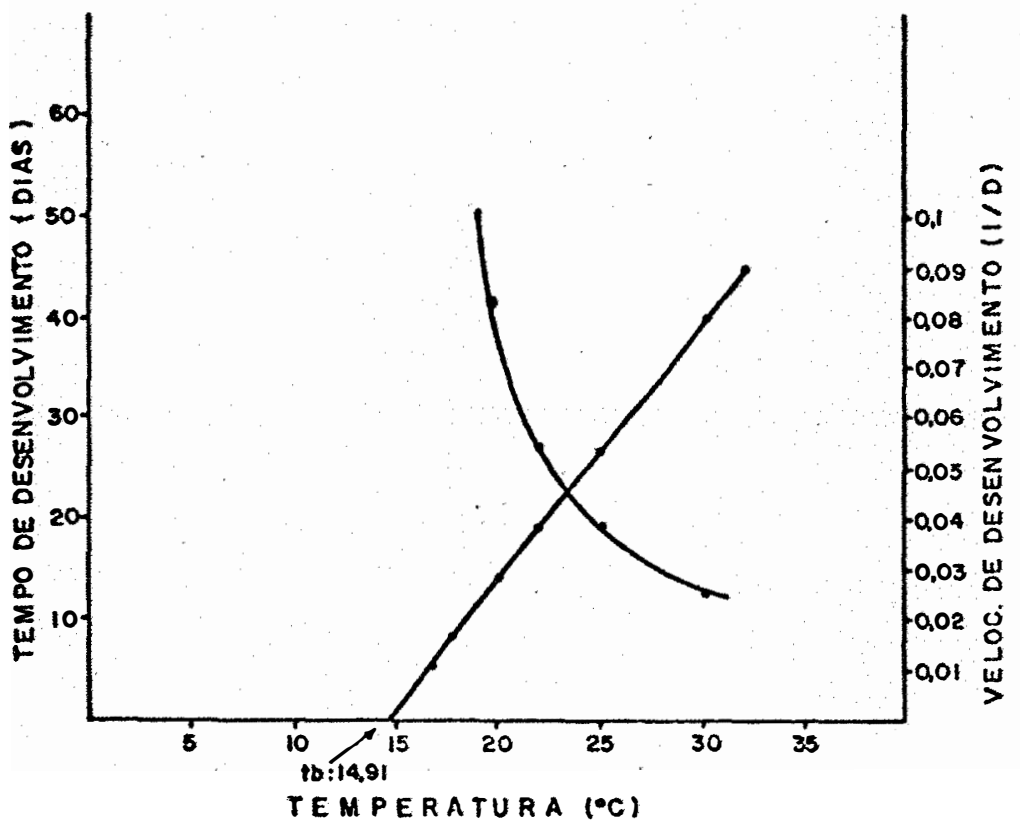

Figura $4^{\circ}$ - Relação entre o tempo de desenvolvimento (dia) e a velocidade de desenvolvimento $(1 /$ dia) de $B$, ovata em função da temperatura em pupas de G. mellonella.

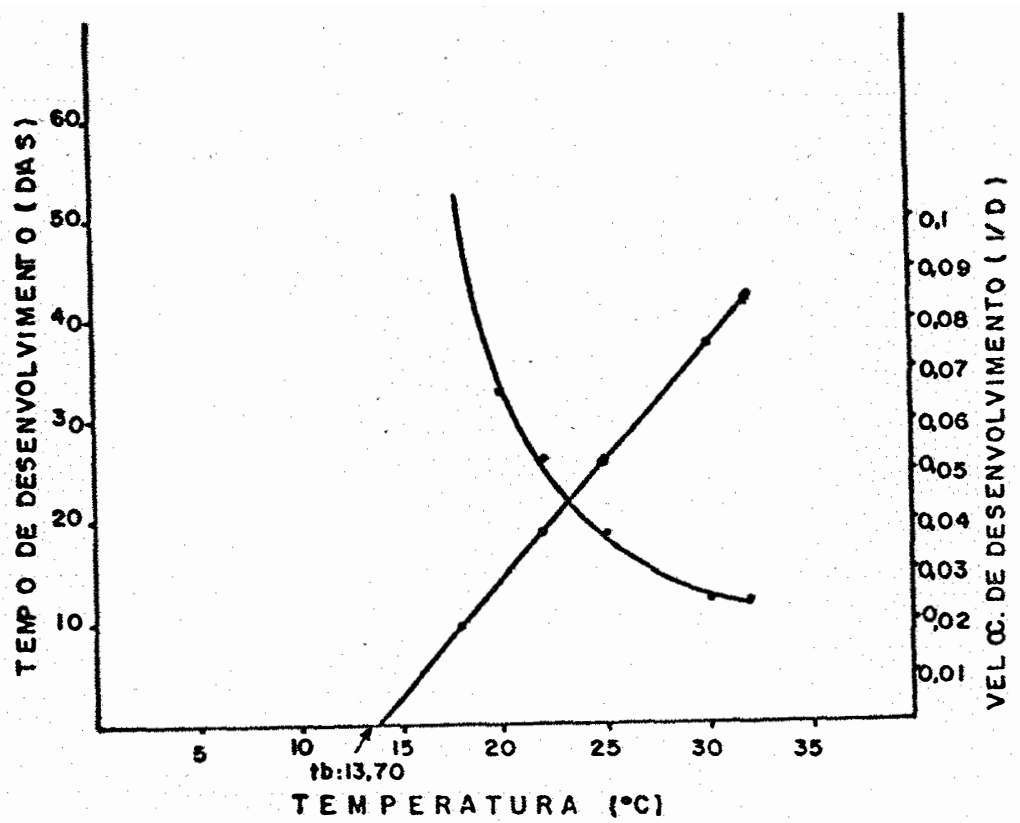

Figura 5 - Relação entre o tempo de desenvolvimento (dia) e a velocidade de desenvolvimento ( $1 /$ dia) de $B$. ovata em função da temperatura em pupas de $D$. saccharalis. 


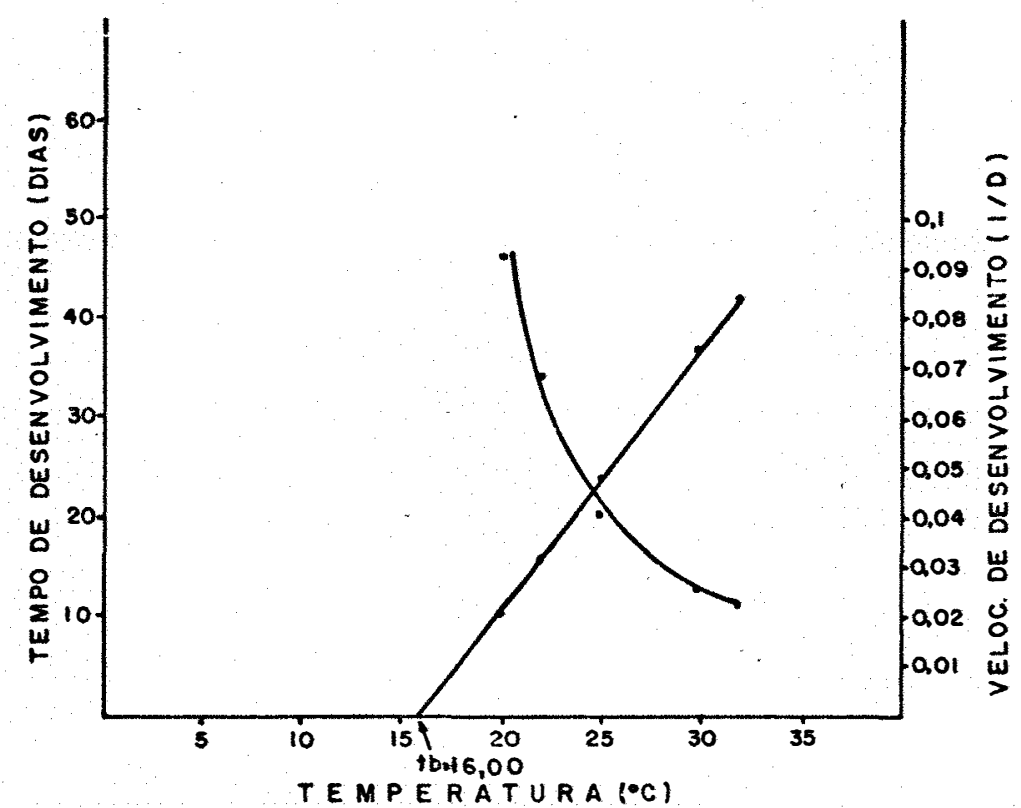

Figura 6 - Relação entre o tempo de desenvolvimento (dia) e a velocidade de desenvolvimento (1/dia) de $B$. ovata em função da temperatura em pupas de A. argillacea.

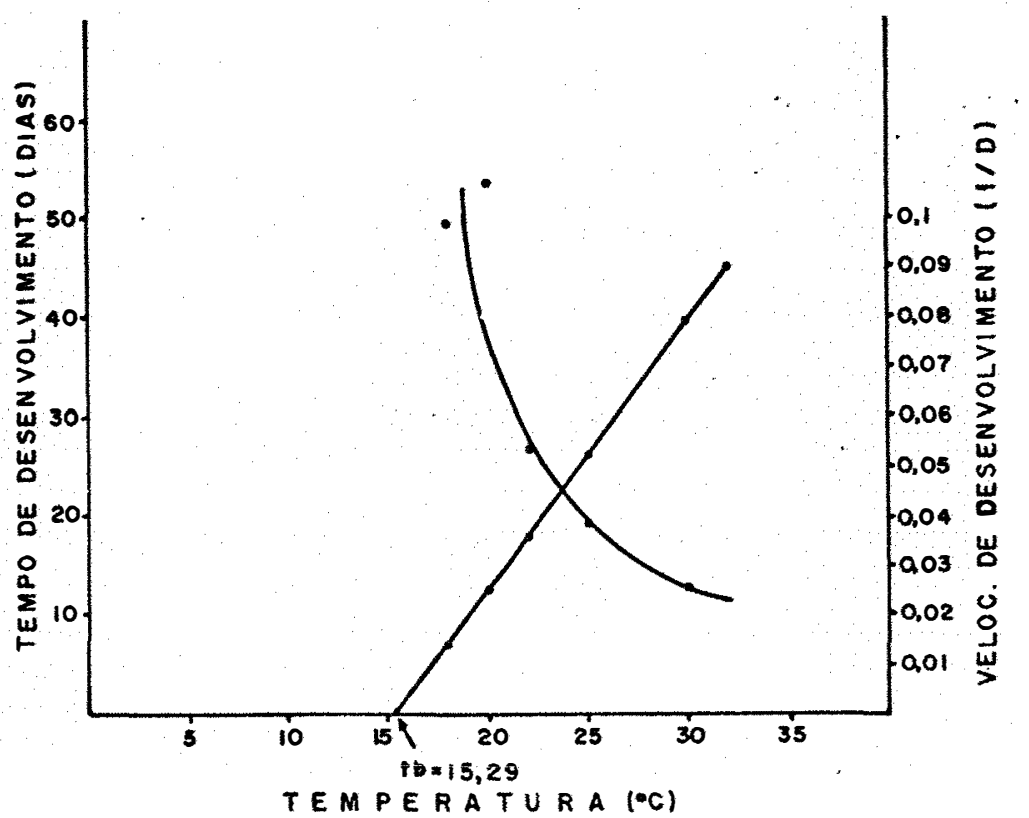

Figura 7 - Relação entre o tempo de desenvolvimento (dia) e a velocidade de desenvolvimento (1/dia) de B. ovata em função da temperatura em pupas de Melanolophia sp. 


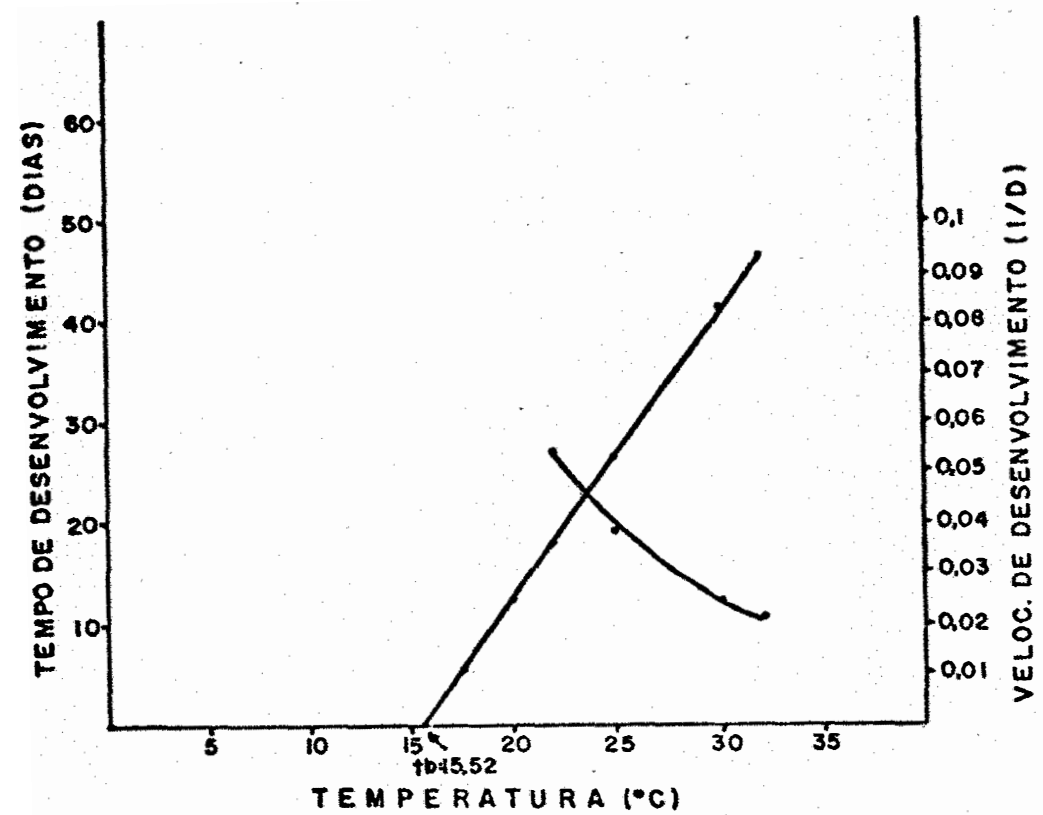

Figura 8 - Relação entre o tempo de desenvoivimento (dia) e a velocidade de desenvolvimento ( $1 /$ dia) de $B$. ovata em função da temperatura em pupas de A. kuehniella.

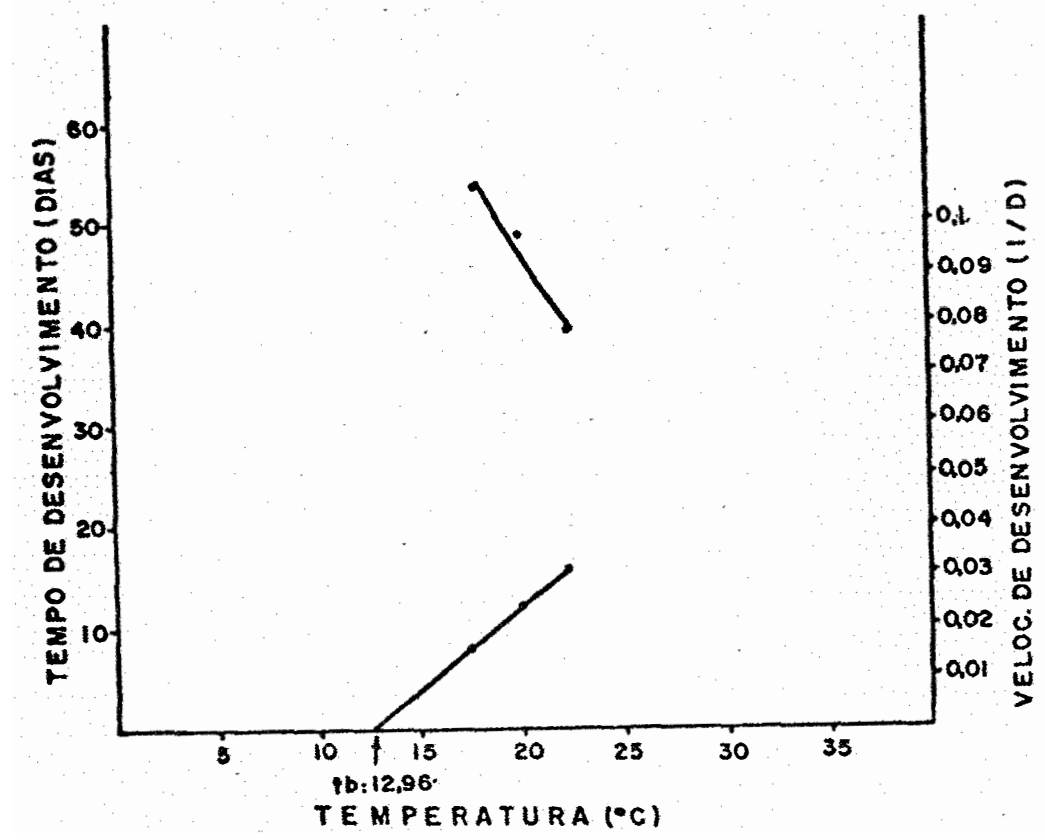

Figura 9 - Relação entre o tempo de desenvolvimento (dia) e a velocidade de desenvolvimento ( $1 /$ dia) de $B$. ovata em função da temperatura em pupas de $A$, ipsilon. 
4.4. Preferéncia para oviposição de B. ovata

0 teste de preferência foi montado com três hospedeiros porque não foi possivel obter material dos demais (Ta bela 35). A preferéncia foi marcante pelas pupas de $G$. mellonella nos primeiros minutos, sendo ovipositadas repetidamente até o final da exposição. A anālise estatística demonstrou, pe 10 teste $F$ (Tabela 36 ), que houve grande significância na oviposição de $B$. ovata nos diferentes hospedeiros.

Tabela 35 - Oviposição e porcentagem de emergência-à 300 C de B. ovata em cinco pupas de G. mellonella, D. saccharalis e A. argillacea durante 30 minutos de exposição.
Hospedeiro
G. mellonella
D. saccharalis
A. argillacea

\begin{tabular}{lrrr}
\hline Oviposição média & 12,33 & 8,50 & 3,33 \\
$\%$ emergência & 93,33 & 90,00 & 40,00 \\
\hline
\end{tabular}


Tabela 36 - Anālise de variância de oviposição de B. ovata em pupas de $G$. mellonella, D. saccharalis e A. argillacea.

\begin{tabular}{lrrrrr}
\hline Causas da variação & G.L. & S.Q. & Q.M. & F & Nivel \% \\
\hline Tratamentos & 2 & 244,778 & 122,389 & $21,81^{\star *}$ & 0,00 \\
Resíduo & 15 & 84,168 & 5,611 & & \\
\hline Total & 17 & 328,946 & & & \\
\hline
\end{tabular}

C.V. $=29,405 \%$

0 teste de Tukey a $5 \%$ de probabilidade, aplicado as médias de oviposição (Tabela 37), evidenciou que B. ovata tem preferência para ovipositar em pupas de G. mellonella. A pre ferēncia para oviposição pode ser ordenada da seguinte maneira: G. mellonella > D. saccharalis > A. argillacea. A provável existēncia de um cairomōnio na pupa de $G$. mellonella pode ter influenciado a preferéncia. LEONARD et alii (1975) obtive ram evidência de que produtos químicos do integumento da mariposa cigana são importantes estimulos para Apanteles melanoscelus $e$ Brachymeria intermedia. Recentemente uma sērie de novos 2acilciclohexano-1,3-diona foram identificados na secreção glan dular da mandíbula da larva de Anagasta kuehniella Zeller (MUDD, 1983). Este autor cita ainda que estes compostos, segundo Mudd e Corbert, têm grande atividade como cairomónios motivando a oviposição do himenōptero parasito Ventura canescens (Grav.). 
A maior oviposição em $G$. mellonella pode ter influenciado o surgimento de maior porcentagem de fémeas, devido ao superparasitismo (FINNEY e FISHER, 1968).

Tabe $1 a 37$ - Teste de Tukey a 5\% de probabilidade para oviposição de B. ova ta em pupas de $G$. mellonella, $D$. saccharalis e $A$. argillacea.

\begin{tabular}{|c|c|c|}
\hline Hospedeiro & Média & \\
\hline G. mellonella & 12,333 & $\mathrm{a}$ \\
\hline D. saccharalis & 8,500 & $b$ \\
\hline A. argillacea & 3,333 & $c$ \\
\hline DMS $=3,549$ & & \\
\hline
\end{tabular}

De 30 pupas encasuiadas de $G$. mellonella oferecidas a B. ovata, por um periodo de 9 horas, 20 apresentaram orificios de oviposição e émergēncia de 4 fêmeas e 10 machos do parasito. Das pupas em que o parasito nao realizou orificio para oviposi ção houve emergência de um macho e, após dissecação, encontrou-se em duas pupas a larva do parasito. O ciclo foi igual aqueles desenvolvidos em pupas não encasuladas à temperatura de 300. C. Esses resultados demonstram que B. ovata é um parasito que oviposita em pupas protegidas por casulo de seda, emboraten 
te ovipositar antes de realizar orificio no casulo e às vezes obtendo sucesso. Observou-se que a fèmea introduz o par de pernas posteriores, no orificio feito no casulo, para imobili zar a pupa no interior do casulo, durante a oviposição.

\section{4:6. LONGEVIDADE EM FUNÇÃO DA ALIMENTAÇÃO}

A longevidade à $26 . \pm 10 \mathrm{C}$ para fémeas e machos de B. ovata foi bastante alterada em função da alimentação (Figuras 10 e 11). Os adultos não alimentados e alimentados com água morreram ao completar cinco dias de $i d a d e$.

A longevidade média dos parasitos quando alimen-tados com mel e água, trocando-se o alimento duas vezes por se mana, foi de 67,2 dias (I.V. $=17$ e 132 dias) para fémeas e fi cou compreendida entre os dados obtidos por PATANA (1979), 75,9 e 49,9 dias para as temperaturas de 25 e $300 \mathrm{C}$, respectivamen-te. Entretanto a longevidade para os machos foi de 58,5 dias ( $I . V .=26$ a 135 dias) sendo menor que a obtida por aquele au-tor nas referidas temperaturas.

Tendo sido comprovado que a longevidade não foi al terada quando os adultos foram submetidas ao regime de jejum e água, novas observações foram feitas alimentando-se adultos dos dois sexos somente com mel. Constatou-se que o início da mortalidade para os machos foi de 89 dias e para fémeas 94 dias. Este tipo de alimentação facilita o manejo da 


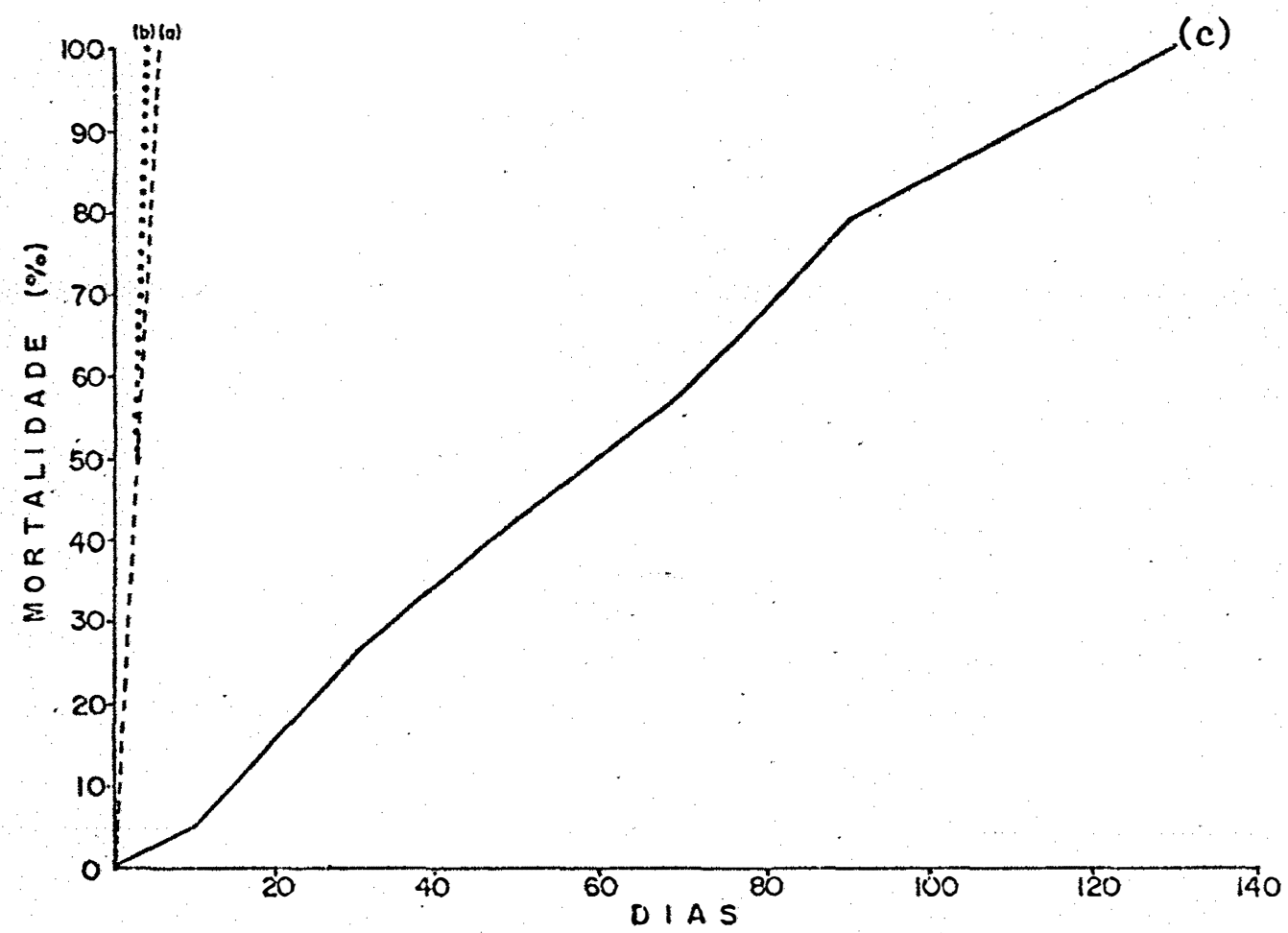

Figura 10 - Porcentagem de mortalidade de fêmeas de B. ovata quando nāo al imentadas (a), al imentadas com água (b) e com mel (c).

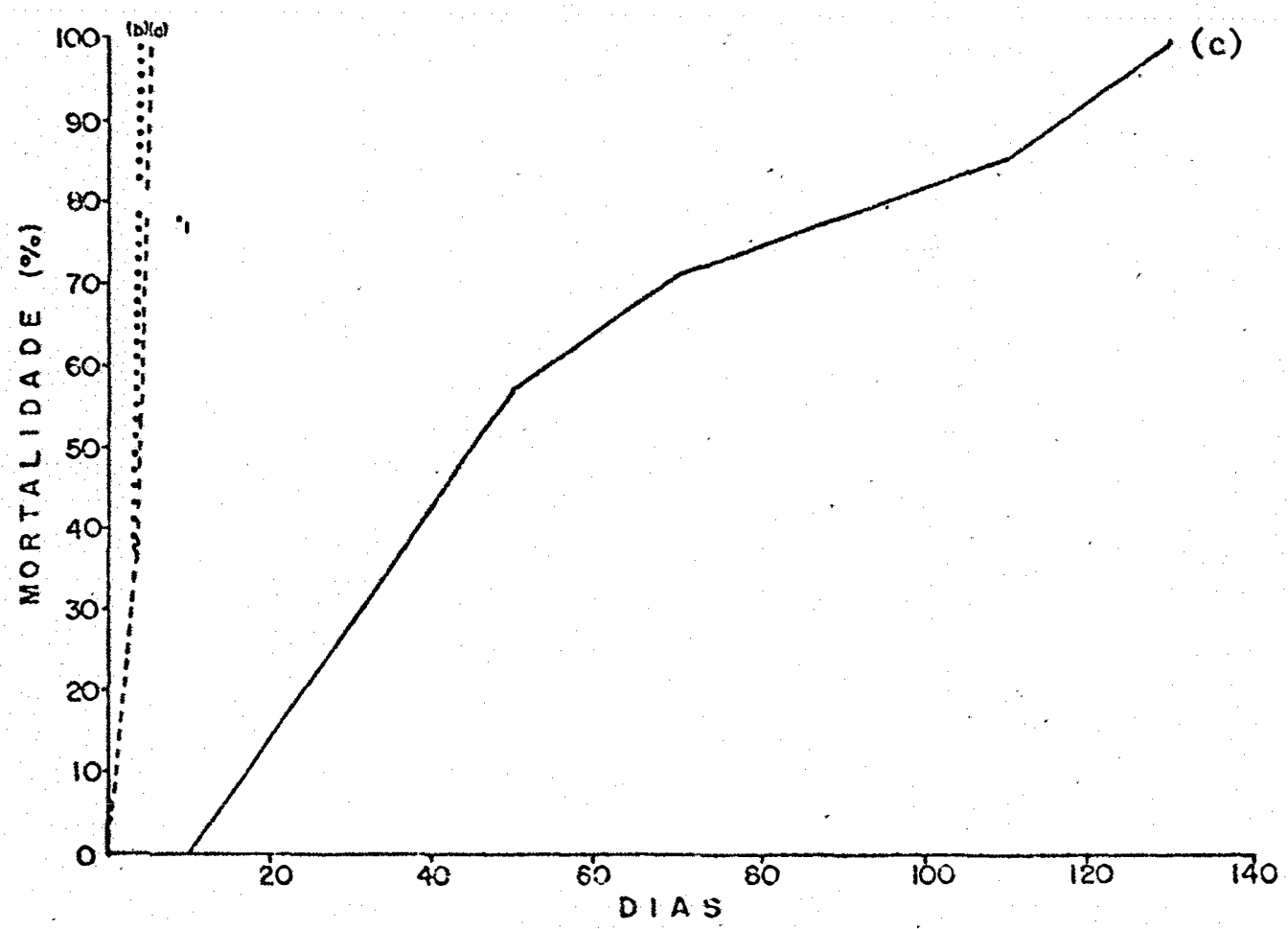

Figura 11 - Porcentagem de mortalidade de machos de $B$. ovata quando não alimentadas (a), alimentados com água (b) e com mel (c). 
população do parasito no laboratório, mas deverá ser trocada se manalmente, evitando que ocorra a fermentação do mel que poderá causar a morte dos parasitos.

Estudos devem ser conduzidos com adultos de $B$. ovata para detectar interações deste parasito com a cultura de eucalipto, já que parasita vārias pragas dessa cultura. Plantas que produzem néctar podem ser testadas quanto a preferência de B. ovata para alimentação, objetivando o plantio em áreas adjacentes aos povoamentos florestais, para manter uma fonte de al $\underline{i}$ mento ao parasito, assim como a outros inimigos naturais.

Parasitóides de Evertria buoliana Schiff., que ataca caule de Pinus na União Soviética, foram muito abun dantes em āreas onde foram localizadas plantas produtcras de nectar (GulU, citado por WESELOH, 1976). Segundo WESELOH (1976) fontes alternativas de alimento para parasitóides florestais são, provavelmente, mais importantes do que geralmente se pensa. A heterogeneidade do meio florestal é mais capaz de suportar adul tos de parasitóides de vida longa, que os mais homogēnos habitats transitórios dos agro-ecossistemas.

A liberação em alta escala de B. ovata em plantios de eucalipto, para controle biológico de pragas, em épocas de florescimento, provavelmente poderá contribuir como agente poli nizador deste vegetal devido à visita do parasito às flores à procura de alimento. A mobilidade e longevidade de B. ovata podem ser características importantes para esta interação, como tambēm polinizar espécies vegetais do sub-bosque. 


\title{
5. CONCLUSÕES
}

\author{
Baseando-se nas observações e resultados obtidos \\ com Brachymeria (B.) ovata (Say, 1824) neste trabalho, con- \\ clui-se que: \\ 1. O hospedeiro afeta o ciclo de vida do parasito. \\ 2. A melhor faixa de temperatura para multiplicação de B. ova \\ ta é de 25 a $30^{\circ} \mathrm{C}$ em Galleria mellonella, sendo que a $30^{\circ} \mathrm{C}$ \\ obtēm-se maior número de parasitos, em função do menor ci- \\ clo e maior porcentagem de emergéncia.
}

3. Galleria mellonella è o hospedeiro alternativo ideal para multiplicação de B. ovata, pela maior porcentagem de emergência de adultos do parasito. 
4. O tamanho do hospedeiro influi no sexo da progênie de $B$. ovata.

5. B. ovata tem preferência para ovipositar em pupas de Galleria mellonella, quando comparado com Diatraea saccha ralis e Alabama argillacea.

6. B. ovata também consegue ovipositar em pupas protègidas por casulo de seda.

7. Os adultos de B. ovata, em laboratōrio, alimentados somen te com mel tiveram maior longevidade.

8. A temperatura afeta o ciclo de vida de B. ovata, apresentando interações com os hospedeiros.

9. A temperatura base de B. ovata desenvolvido nos diferen tes hospedeiros estudados variou de 12,96 a $16,00^{\circ} \mathrm{C}$. 


\section{LITERATURA CITADA}

ASKEW, R.R., 1971. Parasitic insects. New York, American Elsevier Publishing Company, Inc., 316p.

BERTI FILHO, E., 1981. Insetos associados a plantações de espécies do gēnero Eucalyptus nos Estados da Bahia, Espírito Santo, Mato Grosso do Sul, Minas Gerais e São Paulo. Piracicaba, ESALQ/USP, 176p. (Tese de Docēncia Livre).

BORTOLI, S.A. de; J.R.P. PARRA e F.M. LARA, 1982. Parasitismo de Hedylepta indicata (Fabricius, 1775) (Lepidoptera, Pyralidae), na região de Jaboticabal, SP. Anais da Sociedade Entomológica do Brasil, Jaboticabal, 11(1):167-168. 
BURKS, B.D., 1936. The Illinois species of Brachymeria (Hymenoptera, Chalcididae). Transactions of the Illinois state Academy of Science, Urbana (29):251-254.

BURKS, B.D., 1960. A revision of the genus Brachymeria Westwood in America North of Mexico (Hymenoptera: Chalcididae). Transactions of the American Entomological Society, Phila delphia (86):225-273.

COSTA LIMA, A.M., 1962. Himenōpteros. IN: COSTA LIMA, A. M. Insetos do Brasil. Rio de Janeiro, ENA, V.12, pt.2. (Série didātica, nọ 14).

DE SANTIS, L., 1969. Chalcidoideos brasileños parasitos de "Euselasia" (Hymenoptera Y Lepidoptera). Boletin do Museu de Histōria Natural da Universidade Federal de Minas Gerais. Belo Horizonte (4):1-6.

DE SANTIS, L., 1980. Catalogo de los himenopteros brasileños de la série parasitica incluyendo Bethyloidea. Curitiba, Edí tora da Universidade Federal do Paranā, 395p.

DOWDEN, P.B., 1935. Brachymeria intermedia (Nees) a primary parasite, and B. compsilurae (Cwfd.) a secondary parasite, of the gypsy moth. Journal of Agricultural Research, Washington, $50(6): 495-523$. 
FINNEY, G.L. e T.W. FISHER, 1968. Cultivo de insectos entomofagos y sus huespedes. IN: DeBACH, P. Control biológico de las plagas de insectos y malas hierbas. México, Compania Editorial Continental, p. 375-410.

Gallo, D.; O. NAKANO; S. Silveira Neto; R.P.l. CarValho; G. C. de BATISTA; E. BERTI FILHO; J.R.P. PARRA; R.A. ZUCCHI e S. B. ALVES, 1978. Manual de Entomologia Agrícola. São Paulo, Editora Agronómica Ceres. $531 \mathrm{p}$.

GUERRA, M.S., 1973. Bionomia das traças da cera. Piracicaba, ESALQ/USP, 133p. (Dissertação de Mestrado).

HADDAD, M.L. e J.R.P. PARRA, 1984. Métodos para estimar os lí mites térmicos e a faixa ótima de desenvolvimento das diferentes fases do ciclo evolutivo de insetos. Piracicaba, Fundação de Estudos Agrários Luiz de Queiroz, 12p.

HORN, D.J., 1974. Observations on primary and secondary parasitoids of California Oakworm, Phyganidia californica pupae (Lepidoptera, Dioplidae). Pan-Pacific Entomologist, San Francisco, 50(1):53-59.

LEONARD, D.E., B.A. BIERL e M. BEROZA, 1975. Gypsy moth kairo mones influencing behavior of the parasitoids Brachymeria in termedia and Apanteles melanoscelus. Environmental Entomology, Maryland, $\underline{4}(6): 929-930$. 
MUDD, A., 1983. Further novel 2-acylcyclohexane 1,3-diones from lepidopteran larvae. J. Chem. Soc. Perkin Trans., London (I) $: 2161-4$.

OHASHI, 0.S., 1978. Biologia e caracteres morfológicos dife renciais de Eupseudosoma aberrans Schaus, 1905 e Eupseudosoma involuta (sepp, 1852) (Lepidoptera, Arctiidae) e ocorrênciade inimigos naturais. Piracicaba, ESALQ/USP, 99p. (Dissertação de Mestrado).

OHASHI, 0.S., 1984. Biologia e aspectos morfológicos de Brachymeria (Brachymeria) ovata (Say, 1824) (Hymenoptera, Chal cididae) endoparasito de pupas de lepidoptera. Piracicaba, ESALQ-USP, 90p. (Tese de Doutorado).

PATANA, R., 1979. Progeny production. and longevity of individual pairs of Brachymeria ovata on Heliothis virescens in laboratory. Environmental Entomology, Maryland, $\underline{8}(6): 987-988$.

PATANA; R.; C.G. JACKSON e R.E. FYE, 1978. Development of Bra chymeria ovata in six lepidopteran hosts. The Southwestern. Entomologist, (s.l.), $\underline{3}(4): 266-270$. 
ROJAS-ROUSSE, D. e M. BENOIT, 1977. Morphology and biometry of larval instars of Pimpla instigator (F.) (Hymenoptera : Ichneumonidae). Bulletin of Entomological Research, London $(67): 129-141$.

SAVESCU, A., 1965. Constantele dezvoltarii insectelor polivol tine si importanta lor pentru teoria si practica protectiei píantelor. Anelele Institutul Central de Cercetari Agrico1e. Sectiei de Protectia Plantelor. Bucaresti, 3:289-304.

SILVA, A.G.D.A.; C.R. GONÇALVES; D.M. GALVAOO A.J.L. GONÇALVES; J. GOMES; M.N. SILVA e L. SIMONI, 1968. Quarto Catālogo dos Insetos que vivem em plantas do Brasil seus parasitos e pre. dadores. Rio de Janeiro, Deptọ de Defesa e Inspeção Agropecuária, v.1, pt.2.

THOMPSON, S.N., 1981. Essential amino-acid requeriments of four species of parasitic hymenoptera. Comparative Biochemistry Physiology, 0xford (69-A):173-174.

WESEOLOH, R.M., 1976. Behaviour of forest insect parasitoids. IN: ANDERSON, J. e H.K. KAYA. Pespectives in forest entomology. London. Academic press New York. p. 99-110. 
7. APẼNDICE 

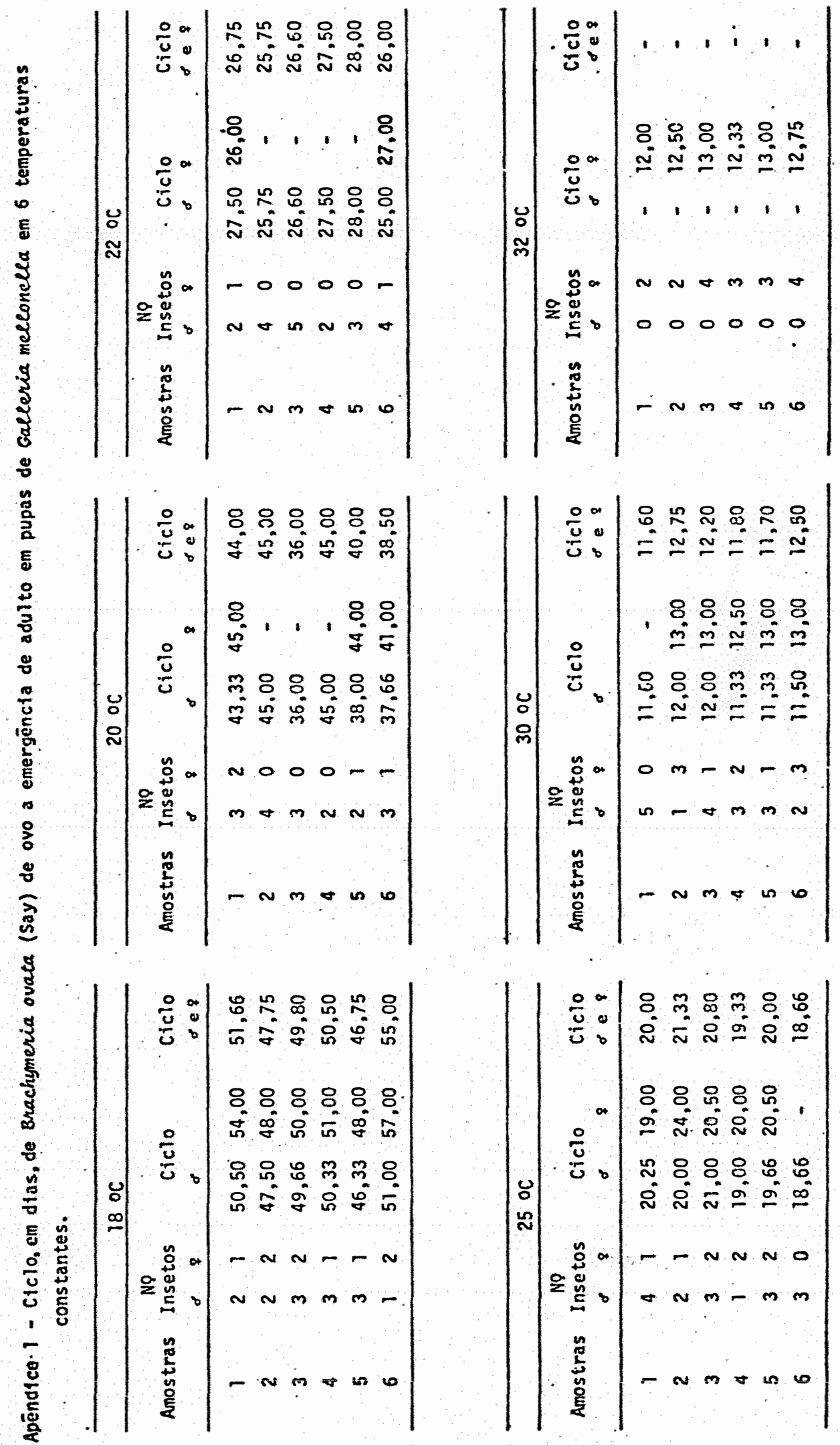

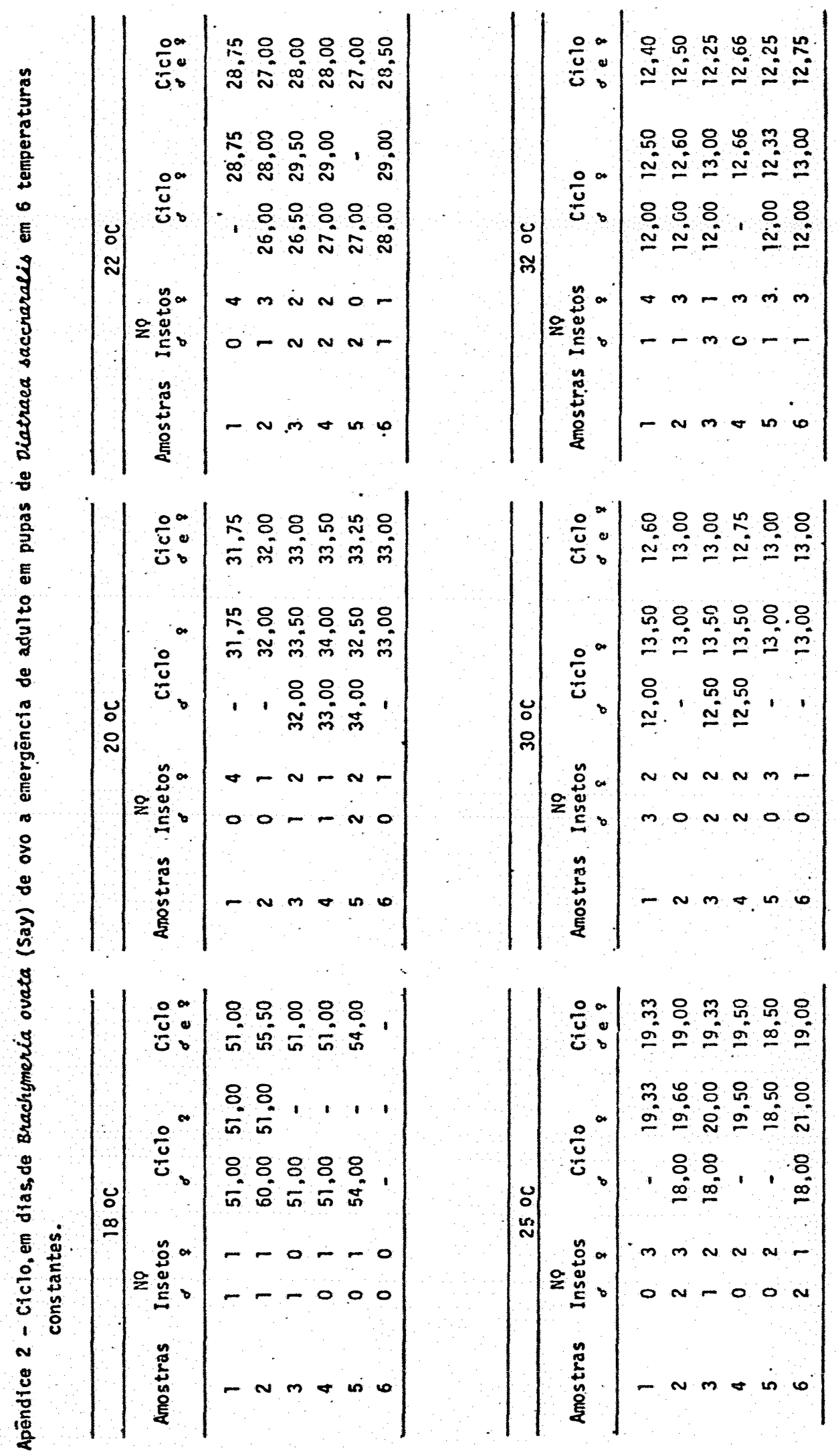

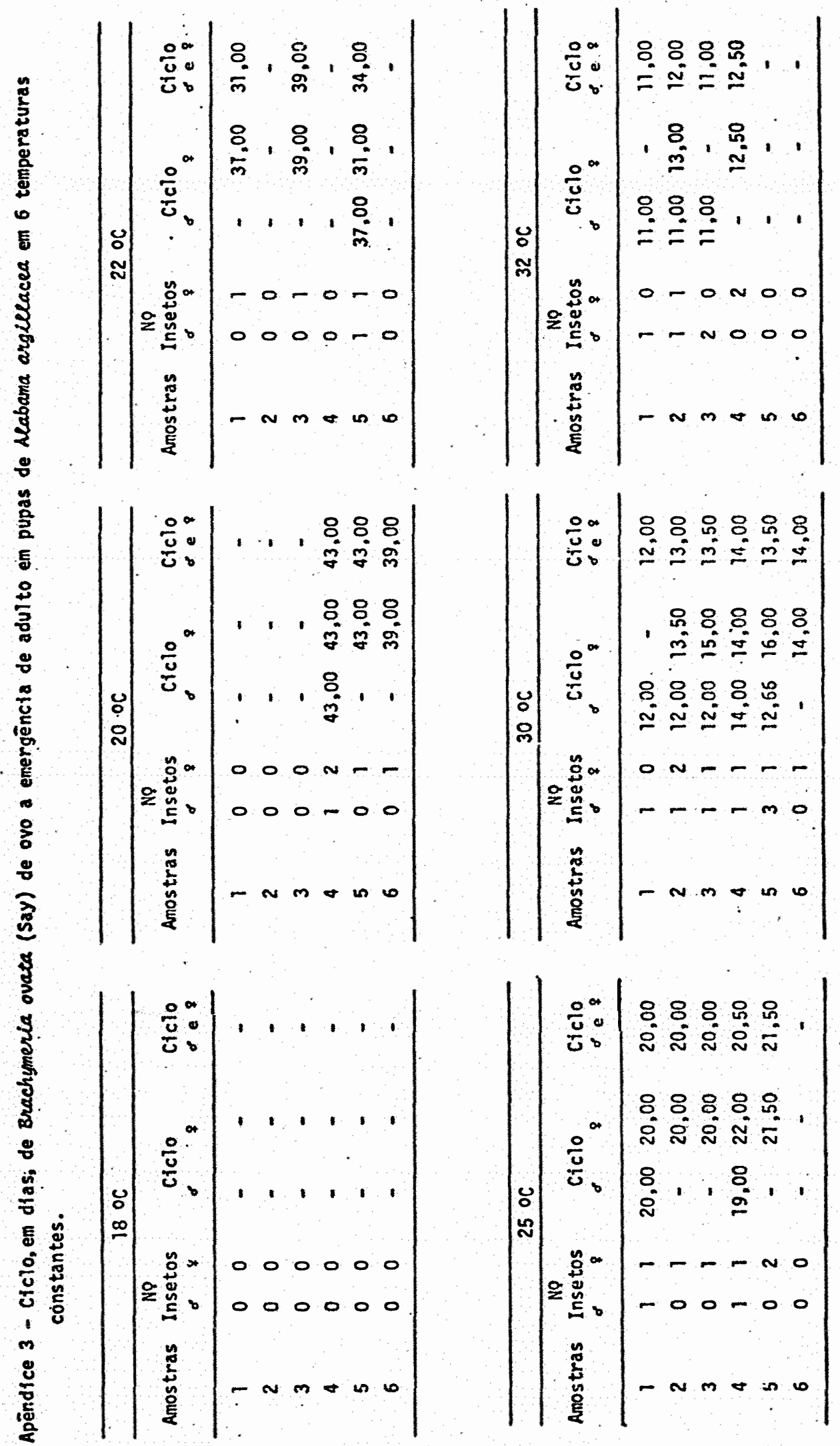


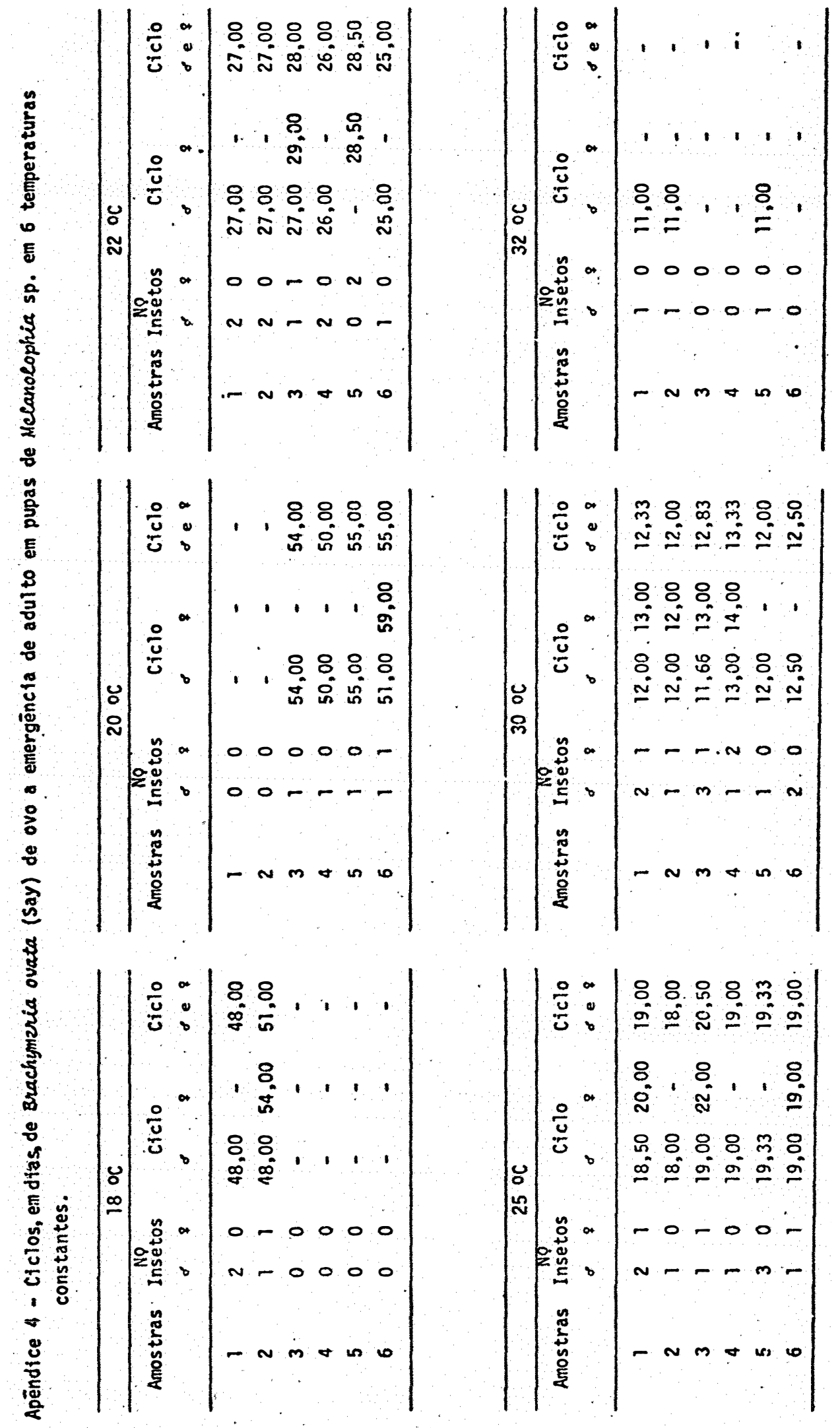




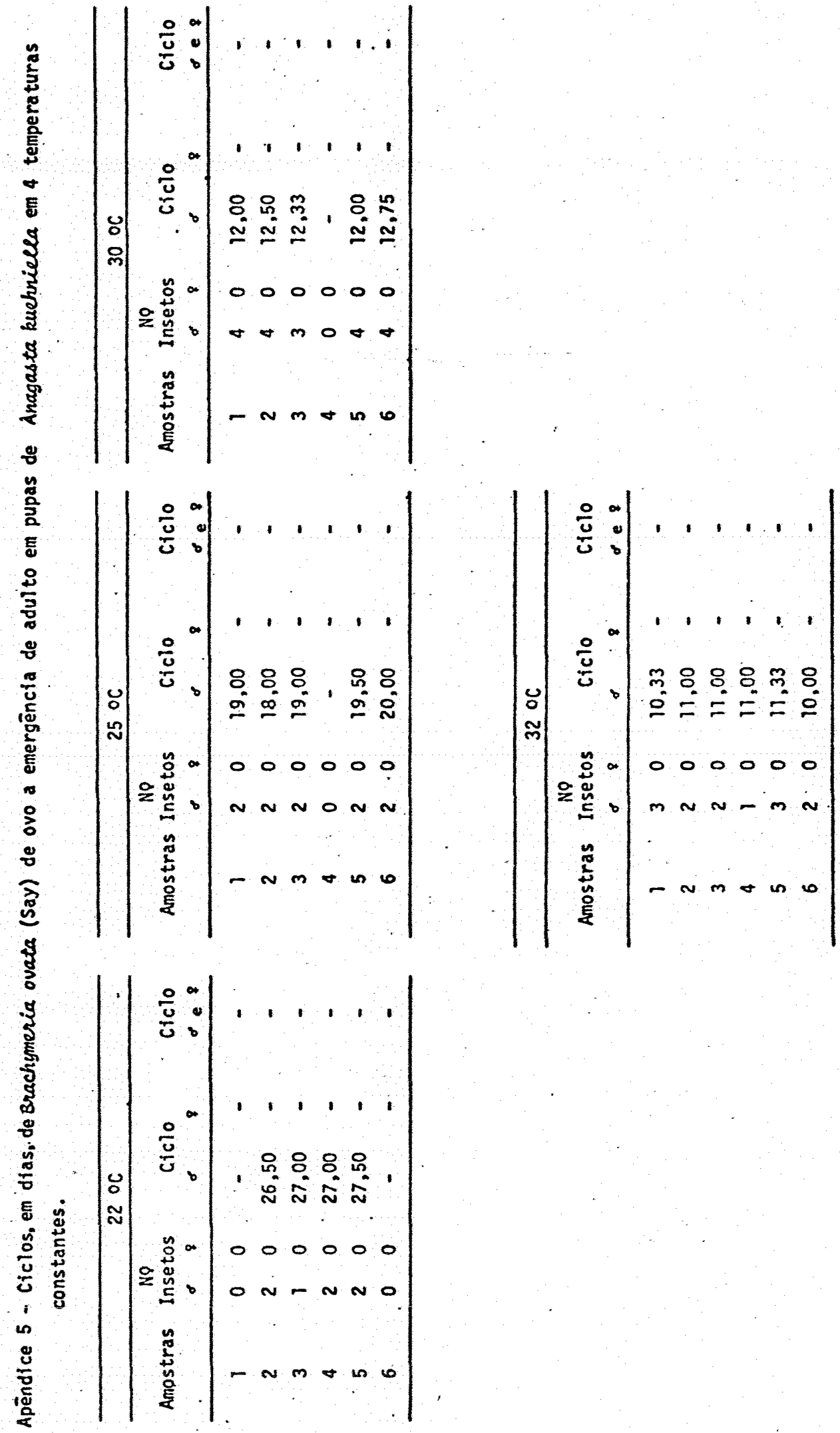




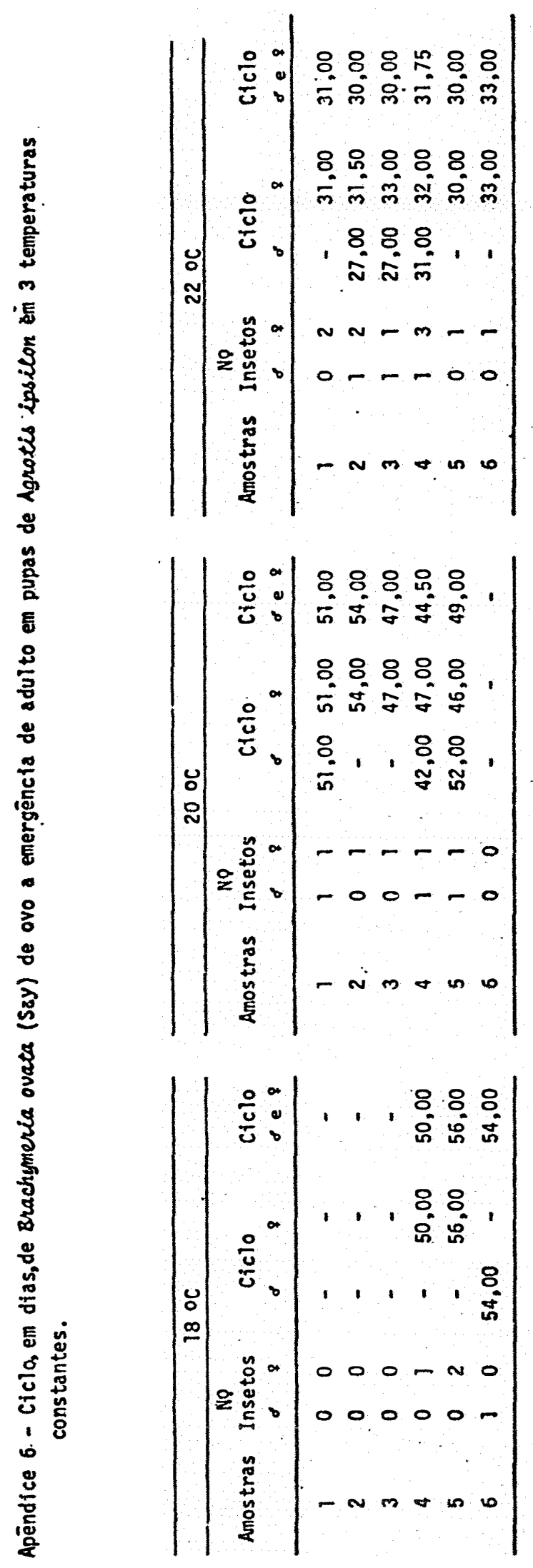


Apêridice 7-Nünero de adultos energidos e porcentagen de emergência de Brachymerica ovata (Say) desenvolvida en pupas de seis hospedeiros sob temperaturas constantes.

E. Galleria mellonetla $(L ., 1750)$
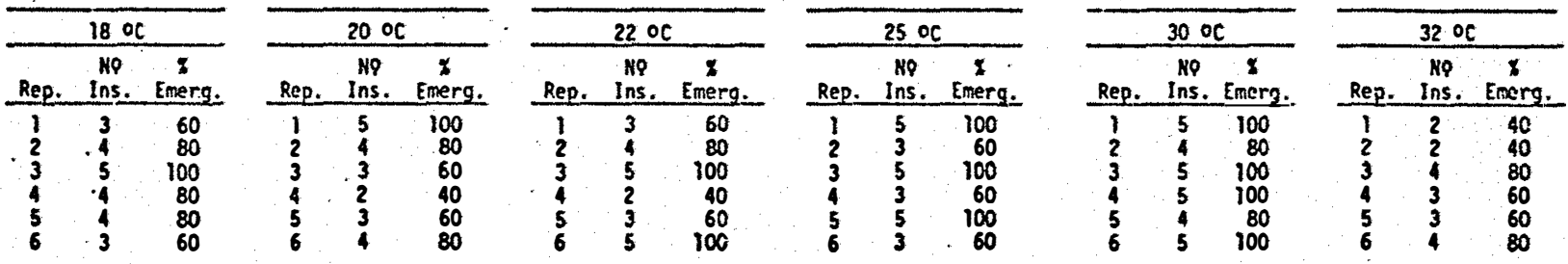

E. Il Diatraea saccharalis (Fabricius. 1794)
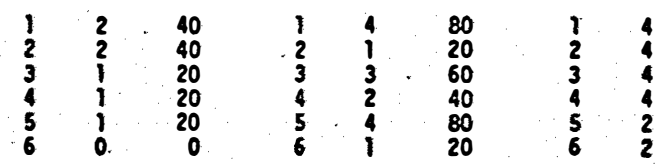

80
80
60
80
40
40
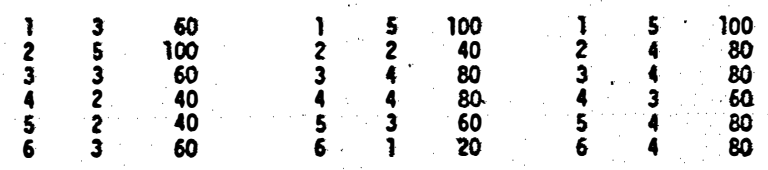

E.III Mabane argillaces (Hobner. 1818)
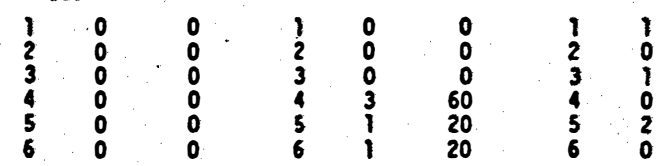

20
0
20
0
40
0

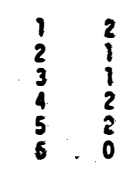

40
20
20
40
40
0
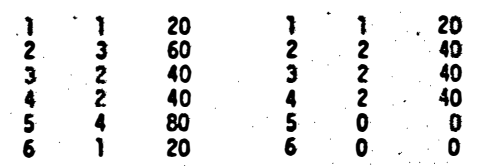

E. Iv Melerolophis sp.
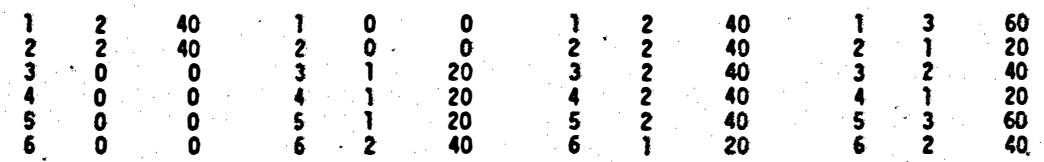

$$
\begin{array}{ll}
1 & 3 \\
2 & 2 \\
3 & 4 \\
4 & 3 \\
5 & 1 \\
6 & 2
\end{array}
$$

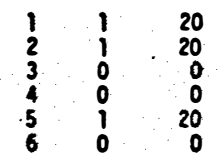

E.y Anagasta kuehrielle (Zeller, 1879)

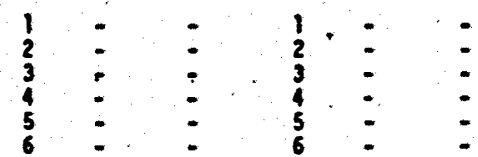

$$
\begin{array}{ll}
1 & 0 \\
2 & 2 \\
3 & 1 \\
4 & 2 \\
5 & 2 \\
6 & 0
\end{array}
$$
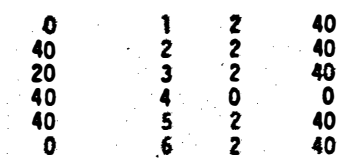

$\begin{array}{ll}1 & 4 \\ 2 & 4 \\ 3 & 3 \\ 4 & 0 \\ 5 & 4\end{array}$

$\begin{array}{lll}1 & 3 & 60 \\ 2 & 2 & 40 \\ 3 & 2 & 40 \\ 4 & 1 & 20 \\ 5 & 3 & 60 \\ 6 & 2 & 40\end{array}$

E. vI Agrotis ipsilon (Hufgnagel, 1776)
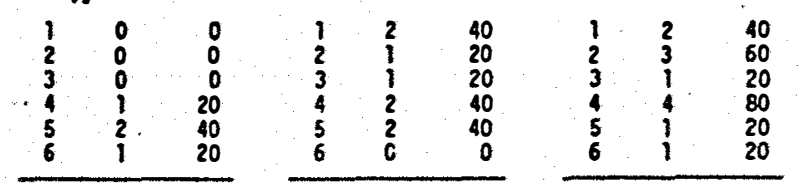
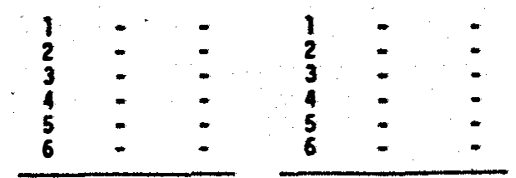